\title{
High-resolution dynamical downscaling of re-analysis data over the Kerguelen Islands using the WRF model
}

\author{
Ricardo Fonseca ${ }^{1}$ (D) Javier Martín-Torres ${ }^{1,2}$ \\ Received: 10 May 2017 / Accepted: 21 February 2018 / Published online: 6 March 2018 \\ (C) The Author(s) 2018. This article is an open access publication
}

\begin{abstract}
We have used the Weather Research and Forecasting (WRF) model to simulate the climate of the Kerguelen Islands $\left(49^{\circ} \mathrm{S}, 69^{\circ} \mathrm{E}\right)$ and investigate its inter-annual variability. Here, we have dynamically downscaled 30 years of the Climate Forecast System Reanalysis (CFSR) over these islands at 3-km horizontal resolution. The model output is found to agree well with the station and radiosonde data at the Port-aux-Français station, the only location in the islands for which observational data is available. An analysis of the seasonal mean WRF data showed a general increase in precipitation and decrease in temperature with elevation. The largest seasonal rainfall amounts occur at the highest elevations of the Cook Ice Cap in winter where the summer mean temperature is around $0{ }^{\circ} \mathrm{C}$. Five modes of variability are considered: conventional and Modoki El Niño-Southern Oscillation (ENSO), Indian Ocean Dipole (IOD), Subtropical IOD (SIOD) and Southern Annular Mode (SAM). It is concluded that a key mechanism by which these modes impact the local climate is through interaction with the diurnal cycle in particular in the summer season when it has a larger magnitude. One of the most affected regions is the area just to the east of the Cook Ice Cap extending into the lower elevations between the Gallieni and Courbet Peninsulas. The WRF simulation shows that despite the small annual variability, the atmospheric flow in the Kerguelen Islands is rather complex which may also be the case for the other islands located in the Southern Hemisphere at similar latitudes.
\end{abstract}

\section{Introduction}

Located in the southern Indian Ocean at about $49^{\circ} \mathrm{S}$ and $69^{\circ}$ E, the Kerguelen Islands (also known as Desolation Islands), are one of the most remote places on Earth located more than $3300 \mathrm{~km}$ to the south-east of Madagascar. Discovered by Yves-Joseph de Kerguelen-Trémarec in February 1772, the islands are known to have an oceanic climate with small daily and annual air temperature ranges and rather windy weather conditions (Varney 1926). Despite the harsh climate, they are home to a wide variety of fauna (Weimerskirch et al. 1989) and flora (Hooker 1879; Frenot et al. 2001). In order to adapt to the extreme windy conditions, most insects like butterflies have

Ricardo Fonseca

Ricardo.Fonseca@1tu.se

1 Division of Space Technology, Department of Computer Science, Electrical and Space Engineering, Luleå University of Technology, SE-971 87 Luleå, Sweden

2 Instituto Andaluz de Ciencias de la Tierra (CSIC-UGR), 18100 Granada, Spain reduced or even no wings (Wallace 1889). Even for humans, the conditions are challenging: as stated in Varney (1926), in Christmas Harbour, located in the north-western part of the island, Sir James Ross was frequently obliged to throw himself on the ground to prevent being blown into the water.

The Kerguelen Islands feature the Cook Ice Cap, a glacier located at a relatively low altitude and then directly influenced by changes in the oceanic and atmospheric circulations (Vallon 1987; Verfaillie et al. 2015). Recently, Favier et al. (2016) has shown that the glacier wastage in the Kerguelen Islands during the 2000s was among the most dramatic on Earth. These authors have also found that most of the climate models from the Coupled Model Intercomparison Project 5 (CMIP5; Taylor et al. 2012) cannot reproduce properly the observed atmospheric conditions over the islands, in particular the precipitation. The main reason behind the fact that general circulation models (GCMs) fail to capture the local climate variability is that they are run at very coarse horizontal resolution (typically no higher than $50 \mathrm{~km}$ ), at which many of the relevant processes, such as the land-sea mask and local topography, are not well simulated. Given the lack of highresolution observational datasets over the region, a highresolution run with a regional climate model $(\mathrm{RCM})$ that 
verifies well against the available observational data and extends over a considerable period of time is currently the best product that can be used to investigate regional and local climate features. A better understanding of the current climate of the Kerguelen Islands and its variability is crucial for glacierrelated studies (e.g. Poggi 1977; Berthier et al. 2009), to better understand projected future climate change and, given the existence of other islands at similar latitudes in the Southern Hemisphere, to have a general idea of their possible local climate conditions.

Being located near $50^{\circ} \mathrm{S}$, the climate of the Kerguelen Islands is strongly influenced by the Southern Hemisphere's mid-latitude storm track. Favier et al. (2016) showed that an

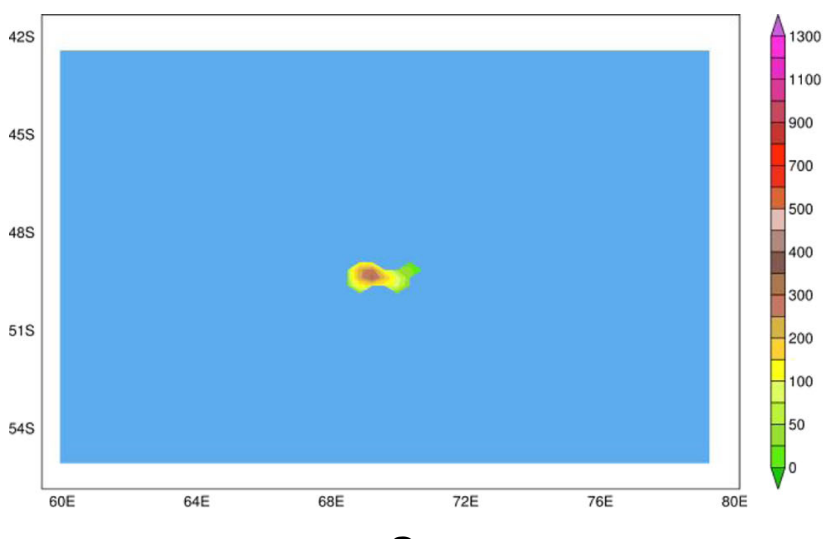

a

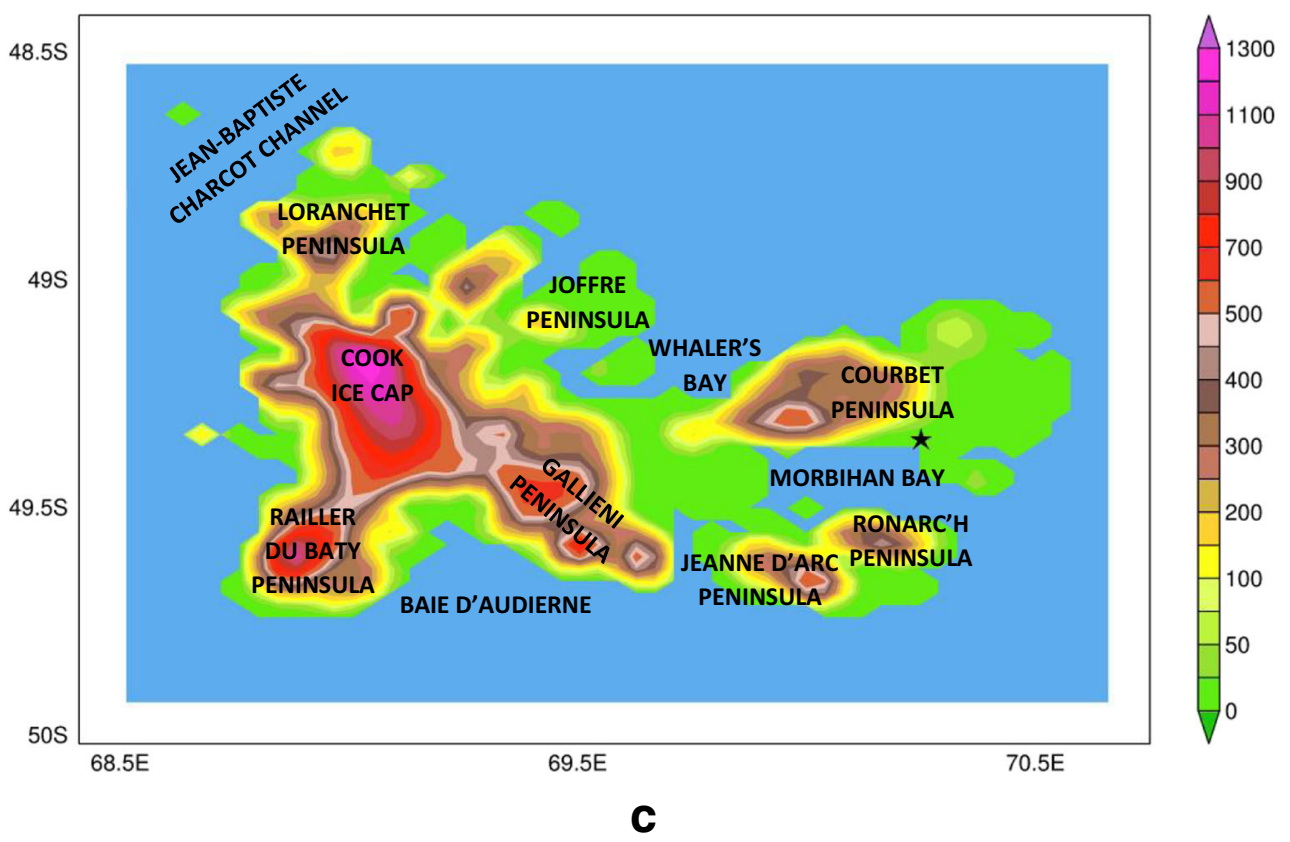

Fig. 1 Spatial extent (with the boundary regions excluded) and orography (m) of the a $27 \mathrm{~km}, \mathbf{b ~} 9 \mathrm{~km}$ and $\mathbf{c} 3 \mathrm{~km}$ WRF domains. In (c), the different regions of the Kerguelen Islands are labelled and the star shows the location of the Port-aux-Français station $\left(49.35^{\circ} \mathrm{S}, 70.25^{\circ} \mathrm{E}\right)$ increase in the Southern Annular Mode (SAM; Marshall 2013) index, the principal mode of atmospheric circulation variability in the Southern Hemisphere, since the mid-1970s has led to a poleward shift of the storm track with higher surface pressures and drier conditions around the Kerguelen Islands and equatorward. Before 1975, the temperature pattern over the southern Indian Ocean resembled the Subtropical Indian Ocean Dipole (SIOD; Behera and Yamagata 2001). In its positive phase, warm sea surface temperatures (SSTs) in the Agulhas and Antarctic circumpolar currents along the southwestern side of the Southern Indian Ocean subtropical gyre affect evaporation rates within the storm track and enhance the precipitation on the islands. Despite the fact that

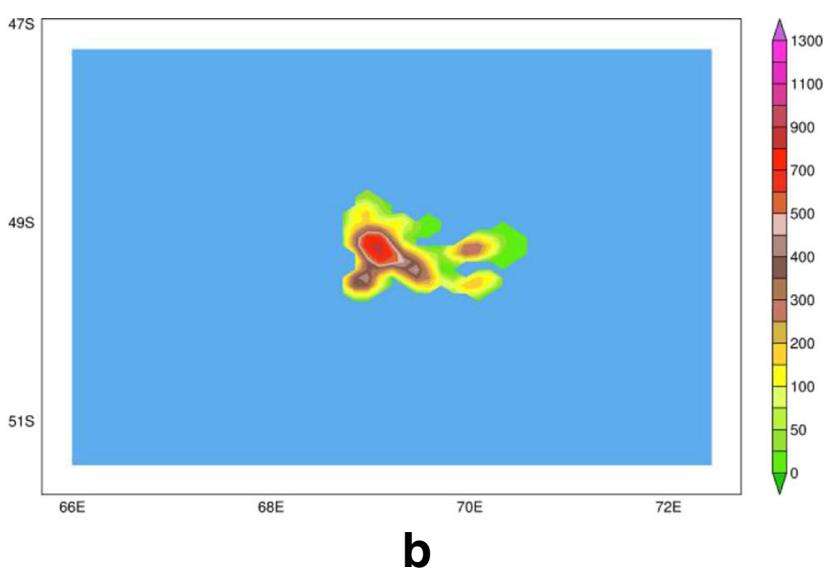


these modes of variability are known to have a significant impact in the weather conditions at Kerguelen, to our knowledge, their local impact (which can be very different in some parts of the islands) has not been investigated. The same is true for tropical modes of variability, e.g. Guinet et al. (1998) found that warm SSTs are typically located south of the Kerguelen Islands within a year of, and between 4.2 and 5.4 years after, an El Niño event. How these anomalous SSTs influence the local climate of the islands is unknown. It is important to note that Guinet et al. (1998) only considered conventional El Niño events. Since the late 1970s, El Niño events have had a different structure with maximum SST anomalies in the central Pacific flanked by colder SSTs to the east and west (Ashok et al. 2007). They are called El Niño Modoki events and are known to have different global impacts (Weng et al. 2007, 2009). As they may occur more frequently in a hypothetical warmer planet (Ashok and Yamagata 2009), it is of interest to consider them as well. The Indian Ocean Dipole (IOD; Saji et al. 1999; Saji and Yamagata 2003) may also have a significant influence in the Kerguelen Islands. The local impacts of these modes of variability are investigated in this study.

In this work, the Weather Research and Forecasting (WRF; Skamarock et al. 2008) model is used. WRF is a fully compressible and non-hydrostatic model that uses a terrainfollowing hydrostatic pressure-based coordinated in the vertical together with the Arakawa-C grid staggering for horizontal discretization. This model has been used for a wide variety of applications including coupled-model applications (e.g. Samala et al. 2013; Zambon et al. 2014), idealised simulations (e.g. Hill and Lackmann 2009; Steele et al. 2013) and regional climate research (e.g. Evans and Westra 2012). Here, the WRF model is used to simulate the climate of the Kerguelen Islands and investigate its inter-annual variability.

In Section 2, details about the model setup and methods used are given. The results of the model evaluation and the climate of the Kerguelen Islands are presented in Section 3 while the impact of different modes of variability on the local climate of the islands is discussed in Section 4. The main conclusions are outlined in Section 5.

\section{Model, datasets and diagnostics}

In this study, the National Centers for Environmental Prediction (NCEP) Climate Forecast System Reanalysis (hereafter CFSR; Saha et al. 2010) 6-hourly data, at a horizontal resolution of $0.5^{\circ} \times 0.5^{\circ}$, is used to initialise and provide boundary conditions to the WRF model version 3.7.1. WRF is run in a nested configuration centered over the Kerguelen
Islands for 30 years (April 1986-March 2016). With the goal of minimising the accumulation of integration errors, and following Lo et al. (2008), the run is broken into overlapping 13month periods which begin at 00UTC on 1st March 1986 and end at 00UTC on 1st April 2016 with the first month regarded as model spin-up after (re-)initialisation with CFSR data. The (re-)initialisation takes place at the end of the summer season in order to keep the winter season within one continuous integration.

The physics parameterizations used include the Goddard six-class microphysics scheme (Tao et al. 1989), the MellorYamada Nakanishi and Niino (MYNN) level 2.5 (Nakanishi and Niino 2004, 2006) for the Planetary Boundary Layer (PBL) with the Monin-Obukhov surface layer parameterization (Monin and Obukhov 1954) and the four-layer Noah land surface model (Chen and Dudhia 2001). The radiation scheme used for both short-wave and long-wave radiation is the Rapid Radiative Transfer Model for Global (RRTMG) models (Iacono et al. 2008) with a spatially and temporally varying climatological aerosol distribution based on Tegen et al. (1997) employed. Cumulus convection is parameterised using the Betts-Miller-Janjić (BMJ; Janjić 1994) scheme. The precipitating convective cloud scheme developed for the BMJ by Koh and Fonseca (2016) is applied in order to account for cumulus cloud-radiation feedbacks. In all experiments, seasonally dependent vegetation fraction and surface albedo are used. A simple interactive prognostic scheme for the sea surface skin temperature (SSKT) based on Zeng and Beljaars (2005), which takes into account the effects of the heat and

Table 1 List of output pressures levels (in $\mathrm{hPa}$ ) and height levels above ground surface (in $\mathrm{m}$ ) to which the raw WRF output data is interpolated

Pressure levels $[\mathrm{hPa}]$

\begin{tabular}{lllll}
1000 & 995 & 990 & 985 & 980 \\
975 & 970 & 965 & 960 & 940 \\
920 & 900 & 850 & 800 & 750 \\
700 & 650 & 600 & 550 & 500 \\
450 & 400 & 350 & 300 & 250 \\
200 & 150 & 100 & 70 & \\
\multicolumn{1}{l}{ Height levels $[\mathrm{m}]$} & & & \\
25 & 50 & 75 & 100 & 125 \\
150 & 175 & 200 & 250 & 300 \\
400 & 600 & 800 & 1000 & 1250 \\
1500 & 1750 & 2000 & 2500 & 3000 \\
3500 & 4000 & 4500 & 5000 & 6000 \\
7000 & 8000 & 9000 & 9500 & 10,000 \\
11,000 & 12,000 & 13,000 & 14,000 & 15,000 \\
\hline
\end{tabular}


radiative fluxes as well as molecular diffusion and turbulent mixing, is added to the model to capture the diurnal variation of the SSKT and allow its feedback to the atmosphere. The lower boundary condition to the SSKT-scheme comes from the 6-hourly SST data from CFSR, linearly interpolated in time to have a continuous-varying forcing on the skin layer.
Also read in from CFSR every $6 \mathrm{~h}$ are the fractional sea-ice coverage and sea-ice depth. The sea-ice albedo in the model is a function of air temperature, skin temperature and snow (Mills 2011). Gravitational settling of cloud drops in the atmosphere is parameterised as described in Dyunkerke (1991) and Nakanishi (2000), whereas cloud water (fog) deposition
Table 2 Bias, normalised bias $(\mu)$, correlation $(\rho)$, variance similarity $(\eta)$ and normalised error variance $(\alpha)$ for the daily mean temperature and dewpoint temperature, daily minimum and maximum temperatures, total daily precipitation amount, daily mean sea-level pressure and horizontal wind speed and daily accumulated snow depth for each season in comparison with NOAA GSOD data for the Portaux-Français station $\left(49.35^{\circ} \mathrm{S}\right.$, $70.25^{\circ} \mathrm{E}$ )

\begin{tabular}{|c|c|c|c|c|c|}
\hline Temperature & Bias $(\mathrm{K})$ & $\mu$ & $\rho$ & $\eta$ & $\alpha$ \\
\hline MAM & -1.212 & -0.500 & 0.631 & 0.989 & 0.376 \\
\hline JJA & -0.946 & -0.756 & 0.879 & 0.981 & 0.138 \\
\hline SON & -1.567 & -1.178 & 0.875 & 0.982 & 0.141 \\
\hline DJF & -1.771 & -1.149 & 0.756 & 0.999 & 0.245 \\
\hline Dewpoint temperature & $\operatorname{Bias}(\mathrm{K})$ & $\mu$ & $\rho$ & $\eta$ & $\alpha$ \\
\hline MAM & -0.039 & -0.137 & 0.598 & 0.998 & 0.403 \\
\hline JJA & -0.015 & -0.010 & 0.861 & 0.999 & 0.140 \\
\hline SON & 0.024 & 0.015 & 0.823 & 0.995 & 0.181 \\
\hline DJF & -0.224 & -0.135 & 0.792 & 0.999 & 0.209 \\
\hline Minimum temperature & $\operatorname{Bias}(\mathrm{K})$ & $\mu$ & $\rho$ & $\eta$ & $\alpha$ \\
\hline MAM & -0.466 & -0.205 & 0.559 & 0.994 & 0.444 \\
\hline JJA & -0.418 & -0.221 & 0.625 & 0.991 & 0.381 \\
\hline SON & -0.707 & -0.462 & 0.727 & 0.981 & 0.287 \\
\hline DJF & -0.511 & -0.347 & 0.681 & 0.996 & 0.322 \\
\hline Maximum temperature & Bias $(\mathrm{K})$ & $\mu$ & $\rho$ & $\eta$ & $\alpha$ \\
\hline MAM & -1.569 & -0.449 & 0.564 & 0.977 & 0.449 \\
\hline JJA & -1.033 & -0.393 & 0.707 & 0.952 & 0.327 \\
\hline SON & -2.147 & -0.837 & 0.753 & 0.970 & 0.270 \\
\hline DJF & -2.492 & -0.956 & 0.685 & 0.999 & 0.316 \\
\hline Precipitation amount & $\operatorname{Bias}(\mathrm{mm})$ & $\mu$ & $\rho$ & $\eta$ & $\alpha$ \\
\hline MAM & 1.011 & 0.129 & 0.057 & 0.986 & 0.944 \\
\hline JJA & 2.019 & 0.293 & 0.127 & 0.975 & 0.876 \\
\hline SON & 1.264 & 0.167 & 0.189 & 0.988 & 0.813 \\
\hline DJF & 0.749 & 0.118 & 0.102 & 0.999 & 0.898 \\
\hline Sea-level pressure & Bias $(\mathrm{hPa})$ & $\mu$ & $\rho$ & $\eta$ & $\alpha$ \\
\hline MAM & 0.944 & 0.098 & 0.625 & 0.998 & 0.376 \\
\hline JJA & 0.998 & 0.315 & 0.968 & 0.999 & 0.033 \\
\hline SON & 0.681 & 0.218 & 0.960 & 0.999 & 0.041 \\
\hline DJF & 0.404 & 0.136 & 0.933 & 0.999 & 0.068 \\
\hline Horizontal wind speed & $\operatorname{Bias}\left(\mathrm{m} \mathrm{s}^{-1}\right)$ & $\mu$ & $\rho$ & $\eta$ & $\alpha$ \\
\hline MAM & -1.466 & -0.413 & 0.523 & 0.995 & 0.470 \\
\hline JJA & -1.270 & -0.464 & 0.733 & 0.999 & 0.268 \\
\hline SON & -1.812 & -0.705 & 0.703 & 0.999 & 0.298 \\
\hline DJF & -2.218 & -0.903 & 0.718 & 0.999 & 0.283 \\
\hline Snow depth & $\operatorname{Bias}(\mathrm{cm})$ & $\mu$ & $\rho$ & $\eta$ & $\alpha$ \\
\hline MAM & - & - & - & - & - \\
\hline JJA & 2.120 & -0.492 & 0.337 & 0.992 & 0.666 \\
\hline SON & - & - & - & - & - \\
\hline DJF & - & - & - & - & - \\
\hline
\end{tabular}


onto the surface due to turbulent exchange and gravitational settling is treated using the simple fog deposition estimation (FogDES) scheme (Katata et al. 2008, 2011). In the WRF simulation, nudging is applied at the lateral boundaries over a four grid-point transition zone while Rayleigh damping is employed in the top $5 \mathrm{~km}$ to the wind components and potential temperature on a time-scale of $5 \mathrm{~s}$ (Skamarock et al. 2008).

The domains used in the model experiments are shown in Fig. 1. The outermost grid is at a horizontal resolution of $27 \mathrm{~km}$ and the innermost grid of $3 \mathrm{~km}$. The cumulus scheme is switched off in the innermost domain where the effect of terrain slopes and shadowing effects from neighbouring gridpoints on the surface solar radiation flux are added. In the outermost grid analysis, nudging towards CFSR is employed. The horizontal wind components and potential temperature perturbation are nudged in the upper-troposphere and lower stratosphere, whereas the water vapour mixing ratio is nudged in the whole troposphere. All fields are relaxed on a time-scale of $1 \mathrm{~h}$. In the vertical 40 levels are considered, concentrated in the PBL, with the lowest level at $\sim 26 \mathrm{~m}$ above the surface and the model top at $30 \mathrm{hPa}$. The output frequency is $3 \mathrm{~h}$ for the first two nests and $1 \mathrm{~h}$ for the innermost grid with only the latter stored. The raw WRF output data is interpolated to a set of 35 height levels and 29 pressure levels, concentrated in the lower atmosphere and listed in Table 1, which is then used for analysis.

The WRF performance is assessed using the diagnostic suite proposed by Koh et al. (2012) which includes the model bias, normalised bias $(\mu)$, correlation $(\rho)$, variance similarity $(\eta)$ and normalised error variance $(\alpha)$. The bias is defined as the mean discrepancy between the model and observations. The normalised bias is given by the bias divided by the standard deviation of the discrepancy between the model and observations. This diagnostic can be used to determine whether the model biases are significant: as shown in Koh et al. (2012), if $|\mu|<0.5$ the contribution of the bias to the root mean square error is less than $\sim 10 \%$ and the biases can be considered not significant when compared to the error variance. The
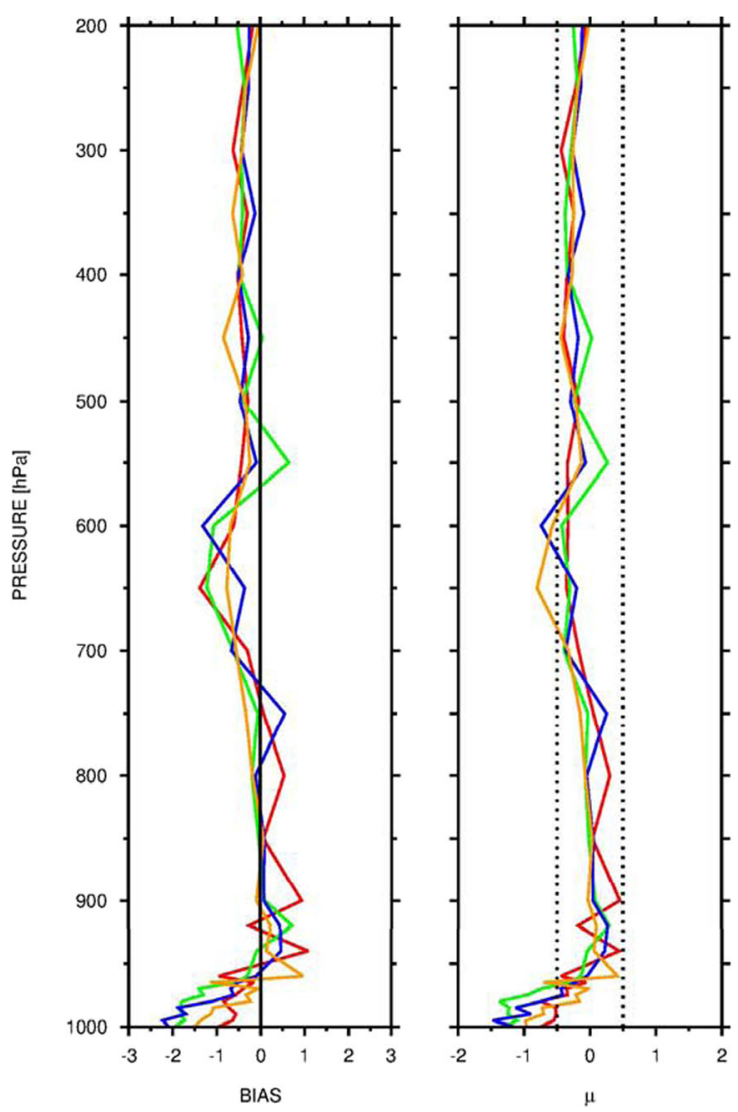

Fig. 2 Vertical profiles of temperature bias (in K), normalised bias $(\mu)$, correlation $(\rho)$, variance similarity $(\eta)$ and normalised error variance $(\alpha)$ averaged over the winter (JJA; red), spring (SON; green), summer (DJF; blue) and autumn (MAM; orange) seasons in a comparison with NOAA
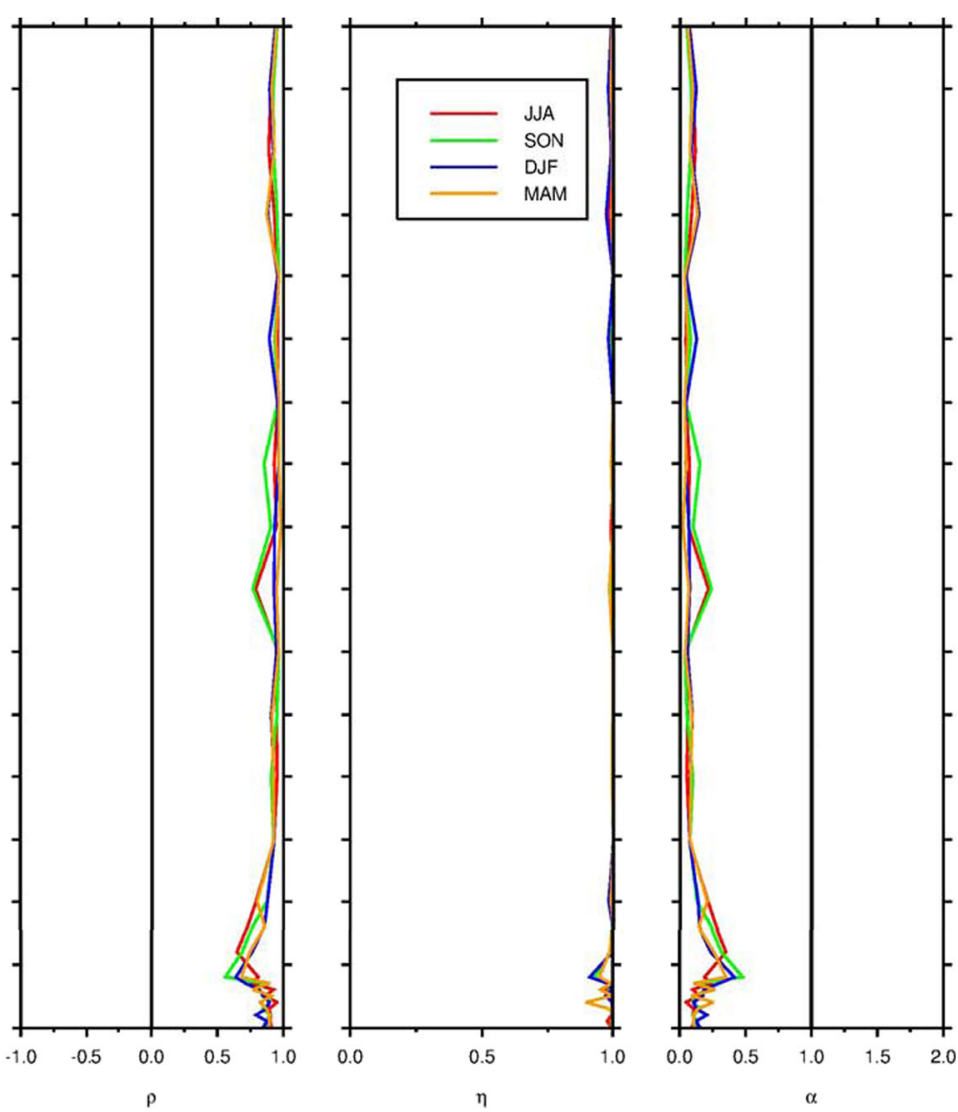

IGRA data for the Port-aux-Français station and for the period April 1986-March 2016. The black dashed lines in the $\mu$ plot correspond to $\mu= \pm 0.5$ with values of $|\mu|<0.5$ indicating that the model biases are not significant 
correlation is a measure of the phase agreement between the modelled and observed signal variations. The variance similarity indicates how well the signal variation amplitude given by WRF agrees with that observed and is defined as the ratio of the geometric mean to the arithmetic mean of the modelled and observed variances. The normalised error variance is the variance of the error arising from the disagreements in phase and amplitude normalised by the combined modelled and observed signal variances. The best performance corresponds to zero bias, $\mu$ and $\alpha$ with the latter requiring both $\rho$ and $\eta$ to be equal to 1 as the three diagnostics are related by the identity below:

$$
\alpha \equiv 1-\rho \eta
$$

For a random forecast based on the climatological mean and variance $\rho=0$ implying that $\alpha=1$. Hence, for a model forecast to be practically useful $\alpha<1$. The verification diagnostics are defined in Eqs. (6)-(11) in Appendix A.

All observational data used for model evaluation comes from the Port-aux-Français station $\left(49.35^{\circ} \mathrm{S}, 70.25^{\circ} \mathrm{E}\right)$. It is taken from the National Oceanic and Atmospheric Administration (NOAA) Global Surface Summary of the Day (GSOD; available online at https://data.noaa.gov/ dataset/global-surface-summary-of-the-day-gsod) and Integrated Global Radiosonde Archive (IGRA; Durre et al. $2006,2008)$ datasets. The evaluation is performed for each season separately: autumn (March-May; MAM), winter (June-August; JJA), spring (September-November; SON) and summer (December-February; DJF). In the model evaluation, the WRF grid-point chosen is not the closest to the location of the Port-aux-Francais station. Instead, it is selected in the following manner: (1) the low-level winds, defined as the winds at the pressure level just above the surface pressure, are bi-linearly interpolated to the location of the station with the reference grid-point the neighbouring grid-point that is upstream (this is particularly important for coastal locations, as is the case for Port-aux-Français, as onshore or offshore flows can lead to very different weather conditions) and (2) a simple elevation correction is applied to the temperature fields using the dry adiabatic lapse rate between the height of the model grid-point and the height of the station.
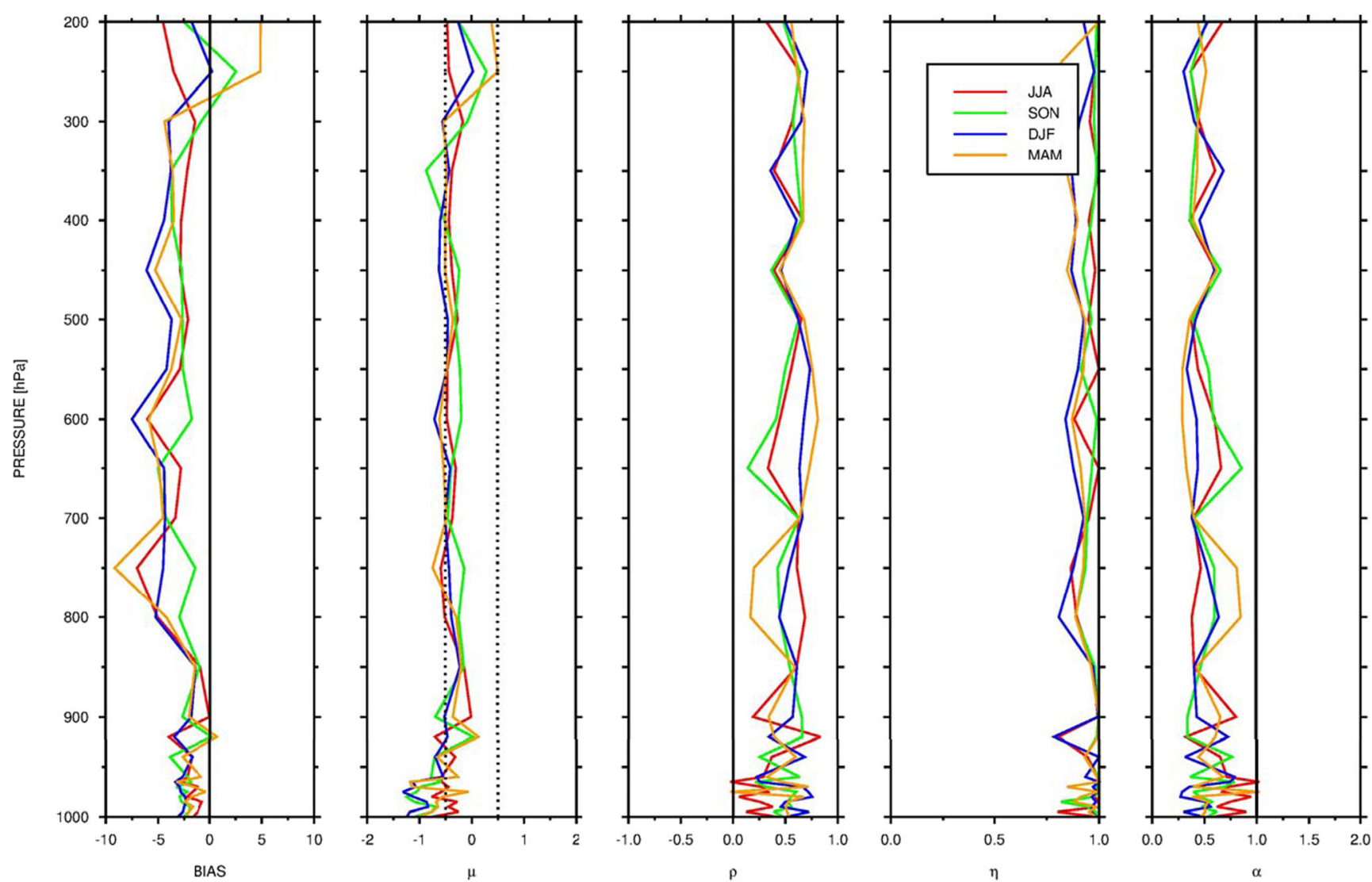

Fig. 3 As Fig. 2 but for the dewpoint depression (the bias is in K) 


\section{Model evaluation and climate}

In this section, the model output is first compared with the NOAA GSOD and IGRA data for the Port-aux-Français station. We then present the seasonal mean values for the surface temperature, precipitation and horizontal wind vector, to illustrate the main features of the climate of the islands.

In Table 2, the diagnostics for several surface and nearsurface fields in comparison with NOAA GSOD data are shown. For all fields and seasons $\alpha<1$, meaning that WRF produces useful forecasts. The largest values of $\alpha$ are obtained for precipitation with this poorer performance being mostly a result of phase errors. The predominance of phase errors over amplitude errors is also seen for the other fields with $\eta$ always higher than 0.95 , whereas $\rho$ can be as low as 0.057 . As the weather conditions at Port-aux-Français are controlled by the passage of transient baroclinic systems, these results indicate that the errors in the timing and location of these systems prevail over the intensity errors. For all seasons, the model's daily-mean temperature is lower than that observed by $\sim 1$ to
$2 \mathrm{~K}$ with the biases being significant in all seasons except in the autumn. Daily minimum and maximum temperatures are also lower by up to $2.5 \mathrm{~K}$, whereas for the dewpoint temperature the magnitude of the biases is much smaller, not exceeding $\sim 0.2 \mathrm{~K}$. A possible explanation for the lower air temperatures is excessive (low-level) cloud cover predicted by the model which may be the case as (1) WRF overestimates the precipitation amount for all seasons and (2) the absolute magnitude of the maximum temperature biases is always larger than that of the minimum temperature biases, for DJF by about a factor of 5. The model sea-level pressure biases are rather small, not exceeding $1 \mathrm{hPa}$, whereas the horizontal wind speeds predicted by WRF are weaker than those observed by up to $\sim 2 \mathrm{~m} \mathrm{~s}^{-1}$ with the biases being significant in spring and summer. The difference between the modelled and reported snow depth in winter shows a positive bias of about $2 \mathrm{~cm}$.

In addition to the surface fields, vertical profiles of temperature, dewpoint depression and horizontal wind are compared with those observed as given by NOAA IGRA. For each available time, a log-pressure interpolation is employed between the
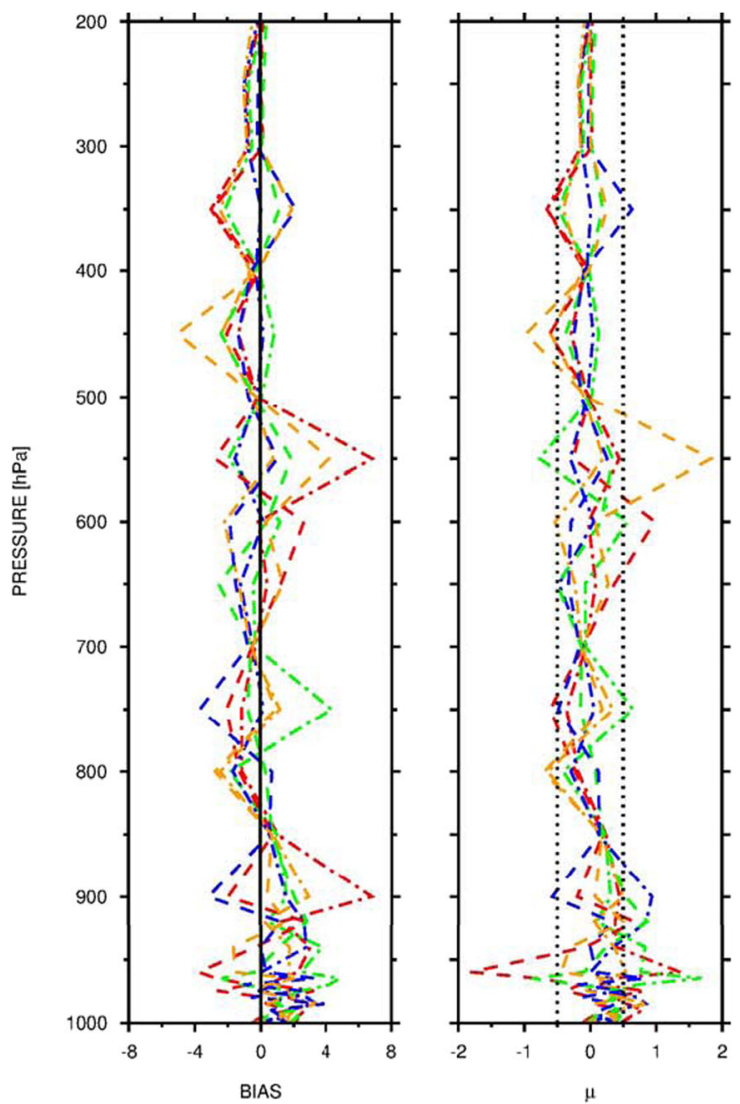

Fig. 4 As Fig. 2 but for the horizontal wind. In the bias (in $\mathrm{m} \mathrm{s}^{-1}$ ) and normalised bias $(\mu)$ plots the coloured dashed-dotted lines show the diagnostics for the zonal wind component and the coloured dashed lines for
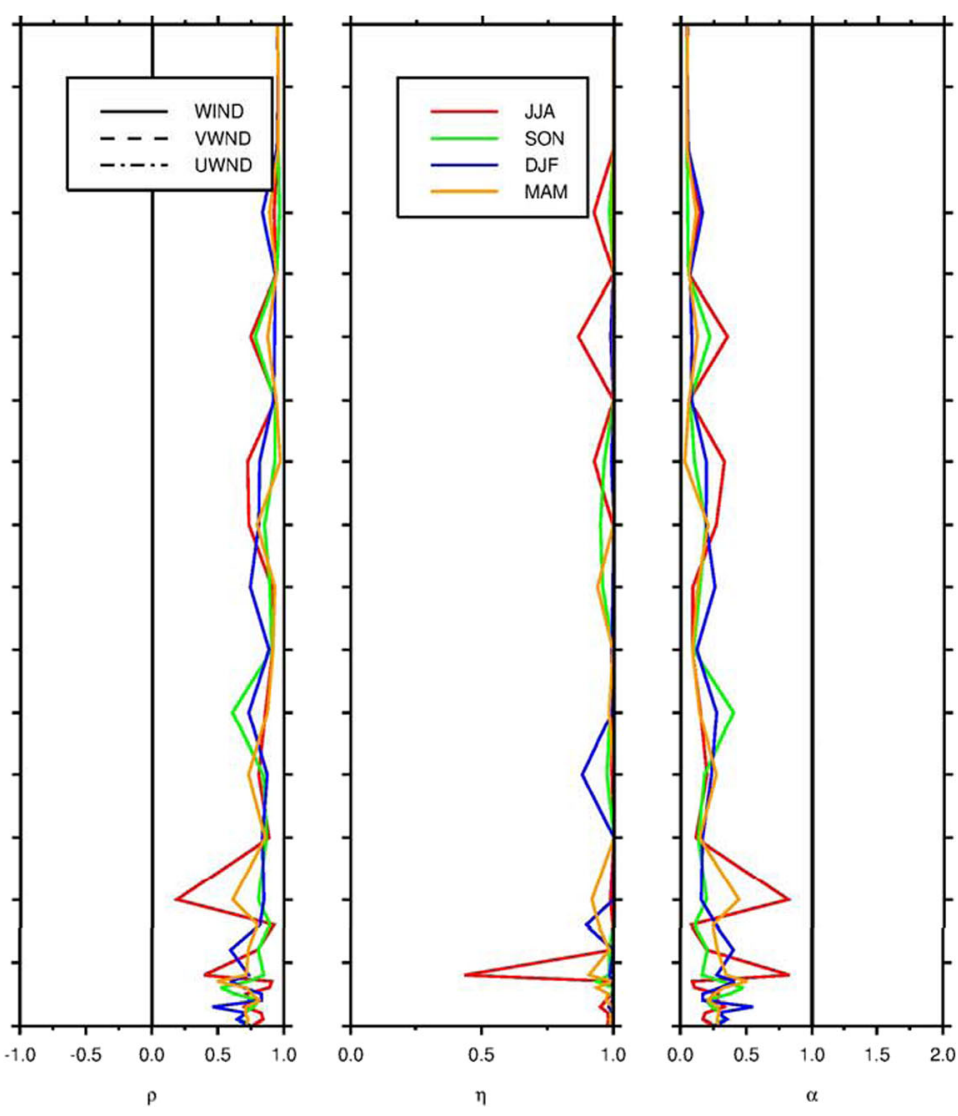

the meridional wind component. The correlation $(\rho)$, variance similarity $(\eta)$ and normalised error variance $(\alpha)$ diagnostics plotted are for the horizontal wind vector (solid line) 
sounding and WRF pressure levels with the diagnostics for each season and pressure range 1000 to $200 \mathrm{hPa}$ shown in Figs. 2, 3 and 4. For temperature, and at lower levels, the diagnostics are similar to those obtained at the surface in comparison with NOAA GSOD data: significant negative biases of the order of 1 to $2 \mathrm{~K}$. At higher elevations, the biases are generally of a smaller magnitude and not significant. An exception is the region between 670 and $570 \mathrm{hPa}$ where the biases drop below $-1 \mathrm{~K}$ and the normalised bias is lower than -0.5 . Increased amounts of low-level cloud leading to enhanced upward longwave radiation flux and radiative cooling may explain the lower temperatures at these levels. At all vertical levels, $\rho$ and $\eta$ are rather high (always above 0.5 ) and $\alpha$ rather low (never exceeding 0.5 ) indicating a good model performance. The diagnostics for the dewpoint depression are not so skillful: despite the fact that $\alpha$ is typically less than 1 , the biases are of a larger magnitude (the negative values imply a more moist environment in the model) and the normalised bias is generally around -0.5 indicating that the biases are borderline significant. The comparison with GSOD data given in Table 2 shows that at the surface WRF is also more moist than observations: the temperature biases are negative and of a larger magnitude than the dewpoint temperature biases leading to a smaller dewpoint depression in the model. The more moist atmosphere is also in agreement with the heavier precipitation (and enhanced cloud cover) predicted by WRF at all seasons. The final field presented is the horizontal wind vector (Fig. 4). For a majority of the levels considered, the model biases are not significant. The sign of the biases varies considerably with height with the zonal wind component generally overestimated (by up to $\sim 7 \mathrm{~m} \mathrm{~s}^{-1}$ ) and the meridional wind component underestimated (by up to $\sim 6 \mathrm{~m} \mathrm{~s}^{-1}$ ) indicating a more north-westerly wind direction in WRF. The other diagnostics ( $\rho, \eta$ and $\alpha$ ) are generally very good with phase errors dominating over amplitude errors except around $950 \mathrm{hPa}$ in winter when the higher values of $\alpha$ ( $0.8)$ are mostly due to a lower $\eta(\sim 0.4)$.

Having verified that WRF simulates well the observed fields at the Port-aux-Français station for which observational
Fig. 5 Two-meter temperature (K) averaged over the autumn (MAM), winter (JJA), spring (SON) and summer (DJF) seasons for the period April 1986-March 2016
AUSTRAL AUTUMN (MAM)

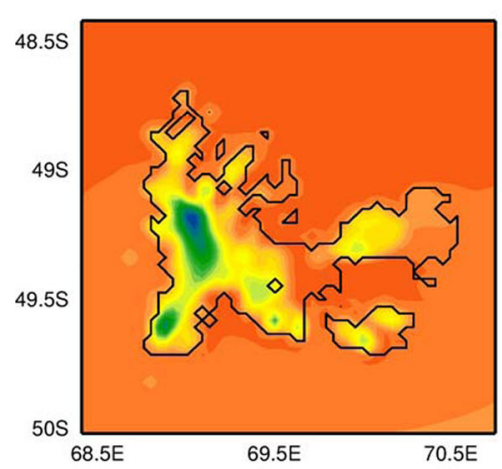

AUSTRAL SPRING (SON)

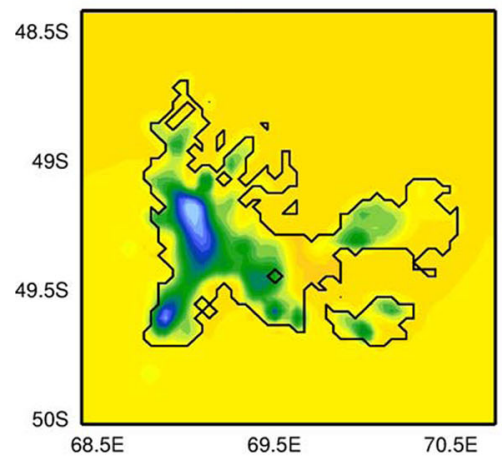

AUSTRAL WINTER (JJA)

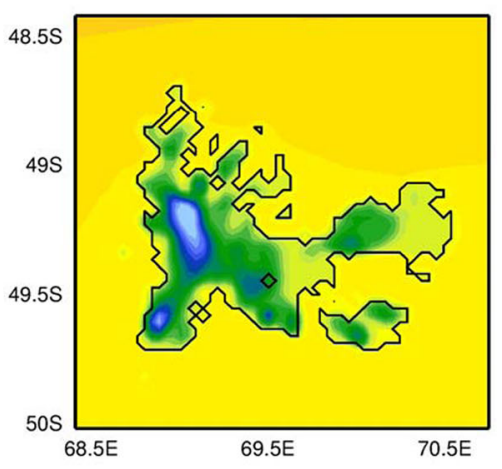

AUSTRAL SUMMER (DJF)

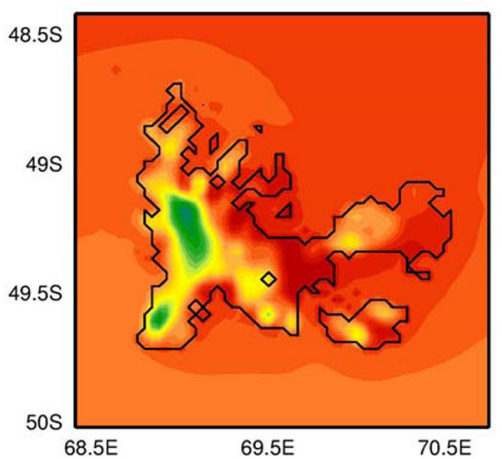

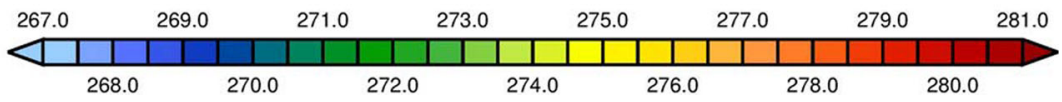


data is available, the seasonal mean climate will now be presented for the whole island. Figures 5, 6 and 7 show the mean 2-m air temperature, accumulated precipitation and 10-m horizontal wind vector, respectively, for the 30-year period (April 1986-March 2016). For simplicity and clarity purposes, the different regions of the Kerguelen Islands will be referred to using their proper names given in Fig. 1c: Loranchet Peninsula in the north-west; Railler du Baty Peninsula in the south-west; Gallieni and Joffre Peninsulas in southern and northern central parts of the island, respectively; Courbet Peninsula on the eastern side; Jeanne d'Arc and Ronarc'h Peninsulas on the south-eastern side. The Whaler's Bay in the north lies between the Joffre and Courbet Peninsulas and the Baie D'Audierne is approximately located between the Railler du Baty and Gallieni Peninsulas in the south-west.

As expected, there is a general decrease in the seasonal mean temperature with elevation with the warmest regions being the eastern side of the Courbet Peninsula (including the Port-aux-Français), the lower elevations between the
Courbet and Gallieni Peninsulas and southeastern and western parts of the Jeanne d'Arc and Ronarc'h Peninsulas. Here, the summer mean temperatures can exceed $281 \mathrm{~K}\left(7.85^{\circ} \mathrm{C}\right)$. At the Cook Ice Cap, the winter mean temperatures are as low as $266.3 \mathrm{~K}\left(-6.85^{\circ} \mathrm{C}\right)$ while in the summer season they are around $0{ }^{\circ} \mathrm{C}$. Over the surrounding ocean, the annual temperature variability is reduced with typical values of $\sim 275 \mathrm{~K}$ $\left(1.85^{\circ} \mathrm{C}\right)$ in winter and $\sim 278 \mathrm{~K}\left(4.85^{\circ} \mathrm{C}\right)$ in summer. As seen in Fig. 6, heavier precipitation is predicted by the model at higher elevations with a seasonal maximum of just above $2700 \mathrm{~mm}$ at the Cook Ice Cap in the winter season. These values seem excessive and may be at least partly the result of the model tendency to overestimate the observed precipitation as is the case for the Port-aux-Français station. The warmest regions of the islands referred above have the lowest total amounts of precipitation for all seasons, comparable to those over the surrounding waters. The precipitation results are consistent with Favier et al. (2016) who found a significant correlation between precipitation and elevation.
Fig. 6 As Fig. 5 but for the accumulated precipitation $(\mathrm{mm})$

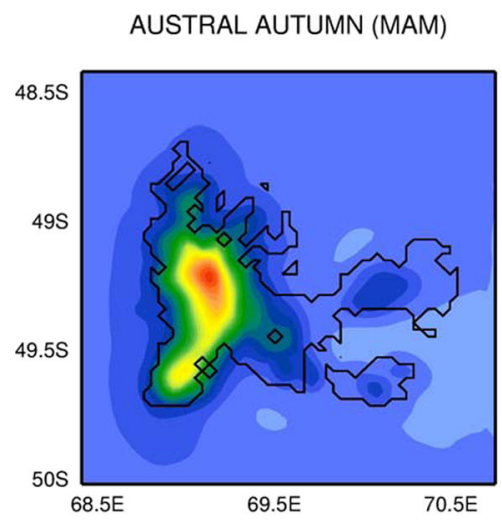

AUSTRAL SPRING (SON)
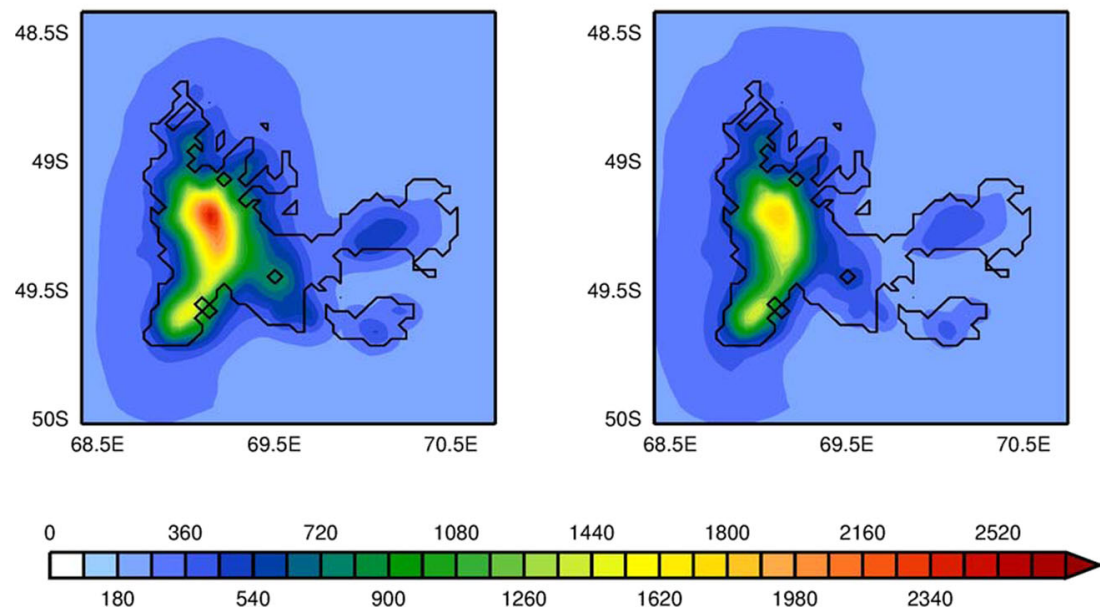

AUSTRAL WINTER (JJA)

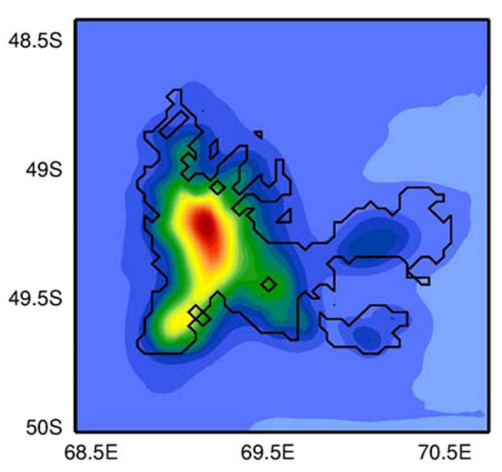

AUSTRAL SUMMER (DJF)

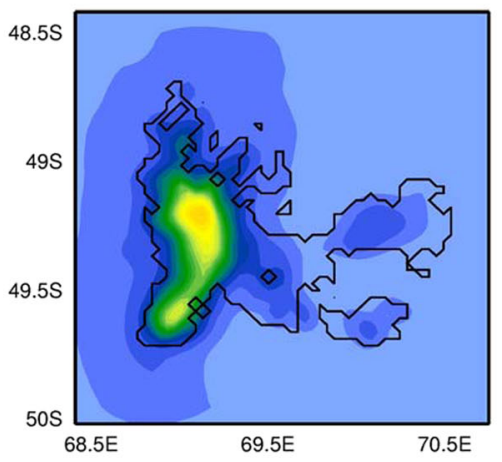


Fig. 7 As Fig. 5 but for the 10-m horizontal wind. The arrows, plotted every 7 th grid-point for clarity purposes, show the wind direction and the shading gives the wind speed $\left(\mathrm{m} \mathrm{s}^{-1}\right)$
AUSTRAL AUTUMN (MAM)

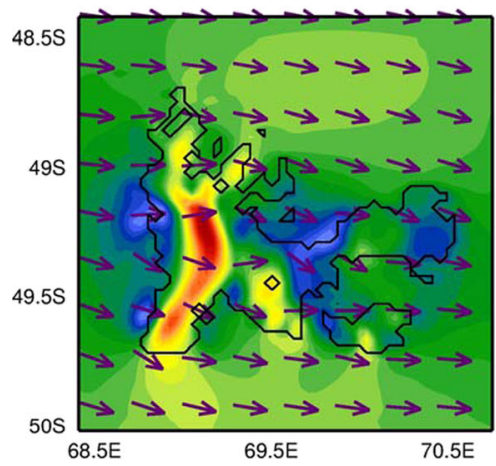

AUSTRAL SPRING (SON)

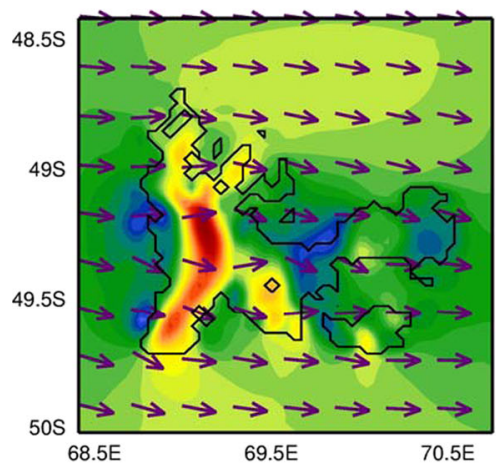

AUSTRAL WINTER (JJA)

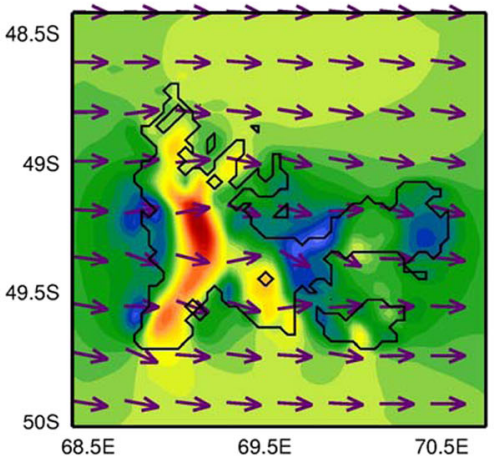

AUSTRAL SUMMER (DJF)

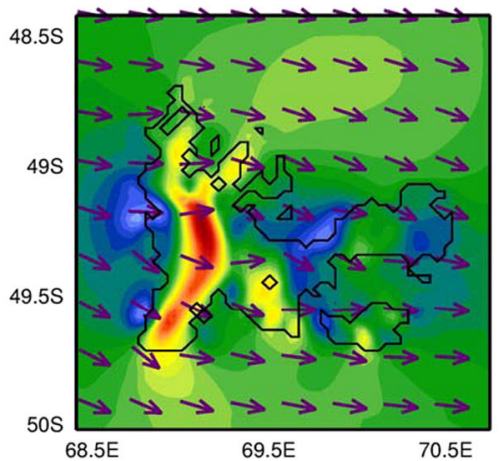

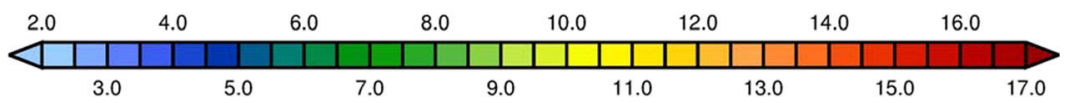

Figure 7 shows the results for the 10-m horizontal wind. There is a small seasonal variability with slightly higher speeds in the winter season. As expected, the strongest winds occur over the high terrain in particular in a banded region that extends from the northern section of the Loranchet Peninsula to the southern section of the Raillier du Baty Peninsula comprising the Cook Ice Cap where seasonal mean values in excess of $17 \mathrm{~m} \mathrm{~s}^{-1}$ are predicted by the model. The most windsheltered areas are south-eastern parts of the Courbet Peninsula, the region between Gallieni and Courbet Peninsulas mainly along the north-western coastline facing the Whaler's Bay, and in parts of the west coast where seasonal mean wind speeds are generally less than $6 \mathrm{~m} \mathrm{~s}^{-1}$. As a result of wind blocking by the topography, seasonal mean speeds are also lower in the region surrounding the Baie D'Audierne. The prevailing wind direction is from the west to north-west with south-westerlies in some central regions and in the northern section of Cook Ice Cap where the flow is forced around the orography.

\section{Linear regression against climate indices}

In this section, we analyse the influence of climate modes of variability on the seasonal climate of the Kerguelen Islands. Favier et al. (2016) showed that changes in the SIOD and SAM lead to variations in the storm track which impacts the Kerguelen Islands. Their influence is analysed here. The SIOD index (Behera and Yamagata 2001) is defined as:

$\mathrm{SIOD}=\mathrm{SST}$ ANOM $[\mathrm{SWIO}]-\mathrm{SST}$ ANOM $[\mathrm{SEIO}]$

where SWIO is the subtropical western Indian Ocean $\left(37^{\circ} \mathrm{S}-\right.$ $27^{\circ} \mathrm{S}, 55^{\circ} \mathrm{E}-65^{\circ} \mathrm{E}$ ) and $\mathrm{SEIO}$ is the subtropical eastern Indian Ocean $\left(28^{\circ} \mathrm{S}-18^{\circ} \mathrm{S}, 90^{\circ} \mathrm{E}-100^{\circ} \mathrm{E}\right)$. The SAM index is taken from Marshall (2013). In addition to SIOD and SAM, tropical modes of variability such as El Niño-Southern Oscillation (ENSO) (both conventional and Modoki types) and IOD are also considered. The conventional ENSO and IOD indices are taken from Lestari and Koh (2016), whereas the ENSO 
Modoki index is taken from Weng et al. (2007). They are defined in Eqs. (3) to (5) below:

$$
\begin{aligned}
& \text { ENSO }=\text { SST ANOM }[\text { NIÑO } 3 \text { MODIFIED REGION }] \\
& \text { IOD }=\text { SST ANOM }[\mathrm{WIO}]-\text { SST ANOM }[\text { EIO }] \\
& \begin{aligned}
\text { ENSO MODOKI } & \left.=\text { SST ANOM }[\mathrm{CP}]-\frac{1}{2} \text { SST ANOM[EP }\right] \\
& -\frac{1}{2} \text { SST ANOM }[\mathrm{WP}]
\end{aligned}
\end{aligned}
$$

where the Niño 3 Modified Region is $\left(4^{\circ} \mathrm{S}-4^{\circ} \mathrm{N}, 90^{\circ} \mathrm{W}-150^{\circ}\right.$ $\mathrm{W})$, WIO is the Western Indian Ocean $\left(10^{\circ} \mathrm{S}-10^{\circ} \mathrm{N}, 50^{\circ} \mathrm{E}-\right.$ $\left.70^{\circ} \mathrm{E}\right)$, EIO is the Eastern Indian Ocean $\left(10^{\circ} \mathrm{S}-0^{\circ} \mathrm{N}, 90^{\circ} \mathrm{E}-\right.$ $\left.110^{\circ} \mathrm{E}\right), \mathrm{CP}$ is the Central Pacific $\left(10^{\circ} \mathrm{S}-10^{\circ} \mathrm{N}, 165^{\circ} \mathrm{E}-140^{\circ}\right.$ $\mathrm{W}), \mathrm{EP}$ is the East Pacific $\left(15^{\circ} \mathrm{S}-5^{\circ} \mathrm{N}, 110^{\circ} \mathrm{W}-70^{\circ} \mathrm{W}\right)$ and WP is the West Pacific $\left(10^{\circ} \mathrm{S}-20^{\circ} \mathrm{N}, 125^{\circ} \mathrm{E}-145^{\circ} \mathrm{E}\right)$. The monthly SSTs used to compute indices (2) to (5) are taken from CFSR with a 5-month running mean applied to smooth out any intra-seasonal variability.

Figures 8 and 9 show the intercept and coefficient of the linear regression of the precipitation rate and $10-\mathrm{m}$ horizontal
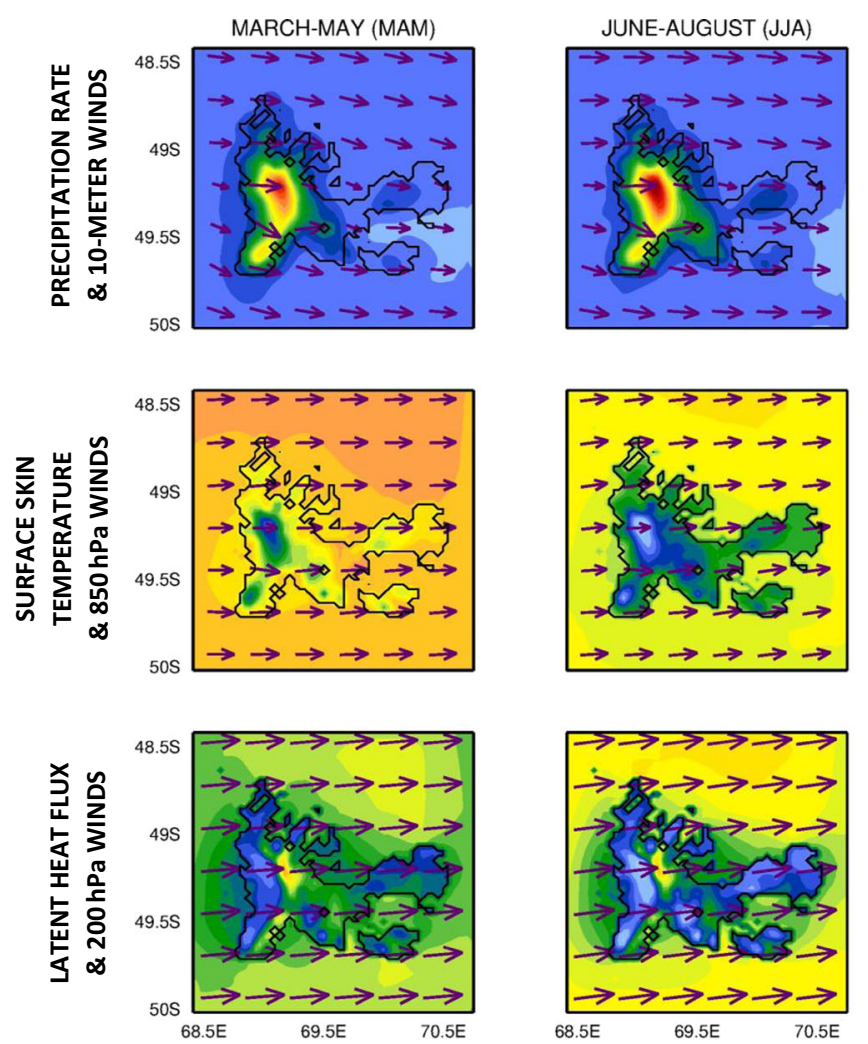

Fig. 8 Regression intercept of (top panels) precipitation rate (shading; $\mathrm{mm}$ day $^{-1}$ ) and 10-m horizontal wind vector (arrows; $\mathrm{m} \mathrm{s}-1$ ), (middle panels) surface skin temperature (shading; $\mathrm{K}$ ) and $850 \mathrm{hPa}$ horizontal wind vector (arrows; $\mathrm{m} \mathrm{s}^{-1}$ ), and (bottom panels) surface latent heat flux wind vector, surface skin temperature and $850 \mathrm{hPa}$ horizontal wind vector and surface latent heat flux and $200 \mathrm{hPa}$ horizontal wind vector against the conventional ENSO index for each season and for the 30 -year period. As this technique constrains the La Niña impacts to be always equal and opposite to the El Niño impacts, only the latter will be discussed.

The precipitation rate for neutral ENSO conditions (regression intercept) is very similar to that of the mean climate shown in Fig. 6 with higher amounts over the high terrain and in the winter season (maximum precipitation rate of $\sim$ $29 \mathrm{~mm}_{\text {day }}{ }^{-1}$ for JJA near the top of the Cook Ice Cap giving a seasonal mean of about $2700 \mathrm{~mm}$ ). The pattern of the surface skin temperature also resembles that of the seasonal mean 2-m temperature given in Fig. 5 with a smaller annual variability over the oceans and higher values at lower elevations in particular between the Courbet and Gallieni Peninsulas and in the Joffre Peninsula when in DJF it exceeds $282 \mathrm{~K}\left(8.85^{\circ} \mathrm{C}\right)$. As a result of the higher ground temperatures, there is increased surface evaporation in these regions as shown by the stronger positive latent heat flux that reaches $80 \mathrm{~W} \mathrm{~m}^{-2}$. The lowest values of the latent heat flux are over the high terrain in the
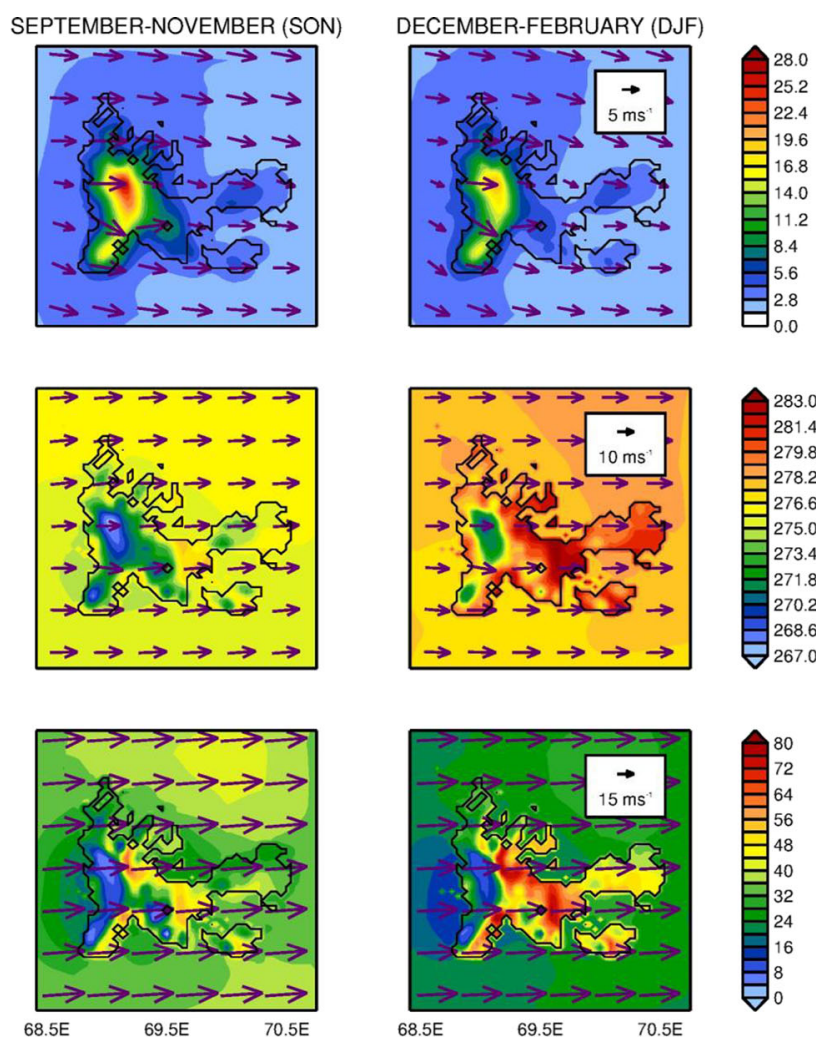

(shading; $\mathrm{W} \mathrm{m}^{-2}$; positive if upwards from the surface) and $200 \mathrm{hPa}$ horizontal wind vector (arrows; $\mathrm{m} \mathrm{s}^{-1}$ ) against the conventional ENSO index for MAM, JJA, SON and DJF 

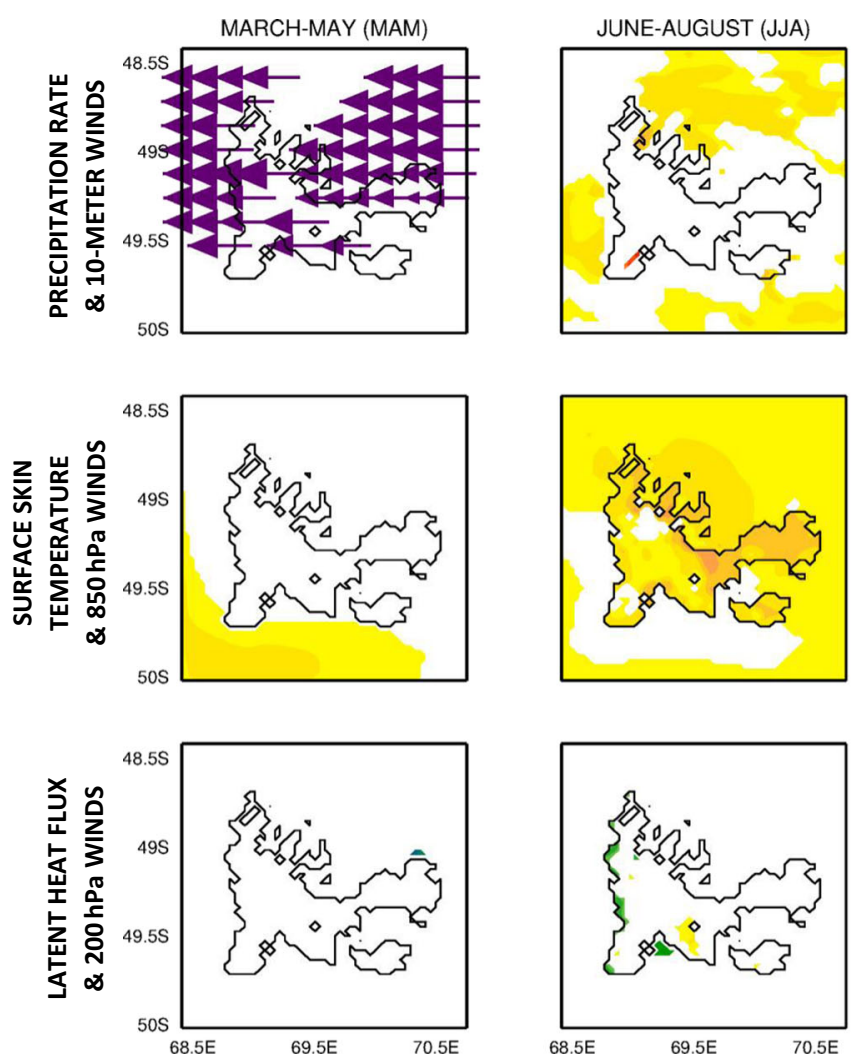

Fig. 9 Regression coefficient of (top panels) precipitation rate (shading; $\mathrm{mm}$ day $^{-1} \mathrm{~K}^{-1}$ ) and $10-\mathrm{m}$ horizontal wind vector (arrows; $\mathrm{m} \mathrm{s}^{-1} \mathrm{~K}^{-1}$ ), (middle panels) surface skin temperature (shading; $\mathrm{K} \mathrm{K}^{-1}$ ) and $850 \mathrm{hPa}$ horizontal wind vector (arrows; $\mathrm{m} \mathrm{s}^{-1} \mathrm{~K}^{-1}$ ), and (bottom panels) surface latent heat flux (shading; $\mathrm{W} \mathrm{m}^{-2} \mathrm{~K}^{-1}$; positive if upwards from the surface) and $200 \mathrm{hPa}$ horizontal wind vector (arrows; $\mathrm{m} \mathrm{s}^{-1} \mathrm{~K}^{-1}$ ) against the conventional ENSO index for MAM, JJA, SON and DJF. Only regression

winter season when the high amounts of rainfall coupled with lower temperatures limit the surface evaporation. The horizontal winds at both low and upper-levels are mostly from the west with higher speeds at $200 \mathrm{hPa}$ (the approximate level of the upper-level jet).

Figure 9 shows the regression coefficients with only those statistically significant at $90 \%$ confidence level being plotted. The precipitation changes are only statistically significant in the solsticial seasons: in the winter season, there is a general increase in precipitation during El Niño events mostly over the oceans, whereas in summer the increase is mainly over land and is more pronounced just to the east of the Cook Ice Cap. While the heavier amounts of precipitation over the oceans in JJA can be attributed to the higher surface skin temperatures (Trenberth and Shea 2005), there is no obvious explanation for what is causing the precipitation increase in DJF. One possibility is that the interaction with ENSO in this season occurs mainly through changes in the diurnal cycle.

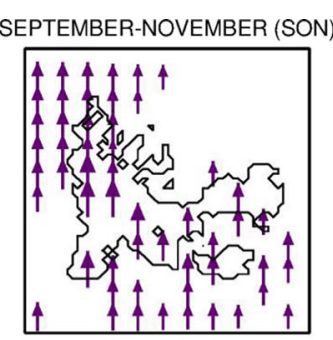

DECEMBER-FEBRUARY (DJF)
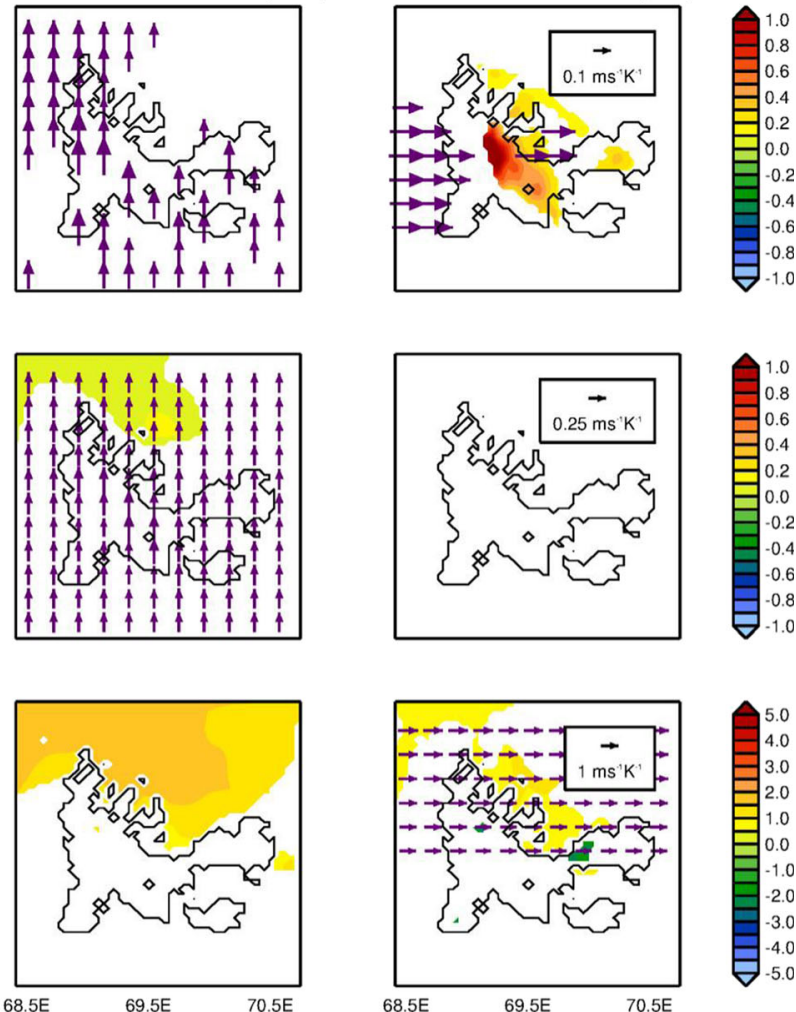

coefficients statistically significant at $90 \%$ confidence level are plotted. For the horizontal wind vector, if the regression coefficients are only statistically significant for the zonal/meridional component, the purple arrow will point in the zonal/meridional direction with the arrowhead filled; if the two regression coefficients are statistically significant the arrowhead is not filled

Figures 10 and 11 show the regression intercept and coefficient, respectively, of the hourly precipitation rate and 10-m horizontal wind vector anomalies for DJF in local solar time (LST). During daytime, higher temperatures on the eastern and central parts of the islands, mainly in the low-level region between the Courbet and Gallieni Peninsulas and in the eastern and southern parts of the Courbet Peninsula, lead to lower pressures compared to those in the highlands to the west. As a result, westerly winds develop over the island. As the background winds are also westerly, the enhanced low-level divergence is likely to lead to drier conditions in particular around the Cook Ice Cap and in the higher elevations of the Loranchet and Railler du Baty Peninsulas. The pattern reverses in the evening and nighttime hours with the anomalous easterly winds that arise in response to the higher pressures to the east converging with the background westerly winds and giving rise to increased amounts of precipitation more significant over the highlands to the west. The diurnal cycle for neutral 

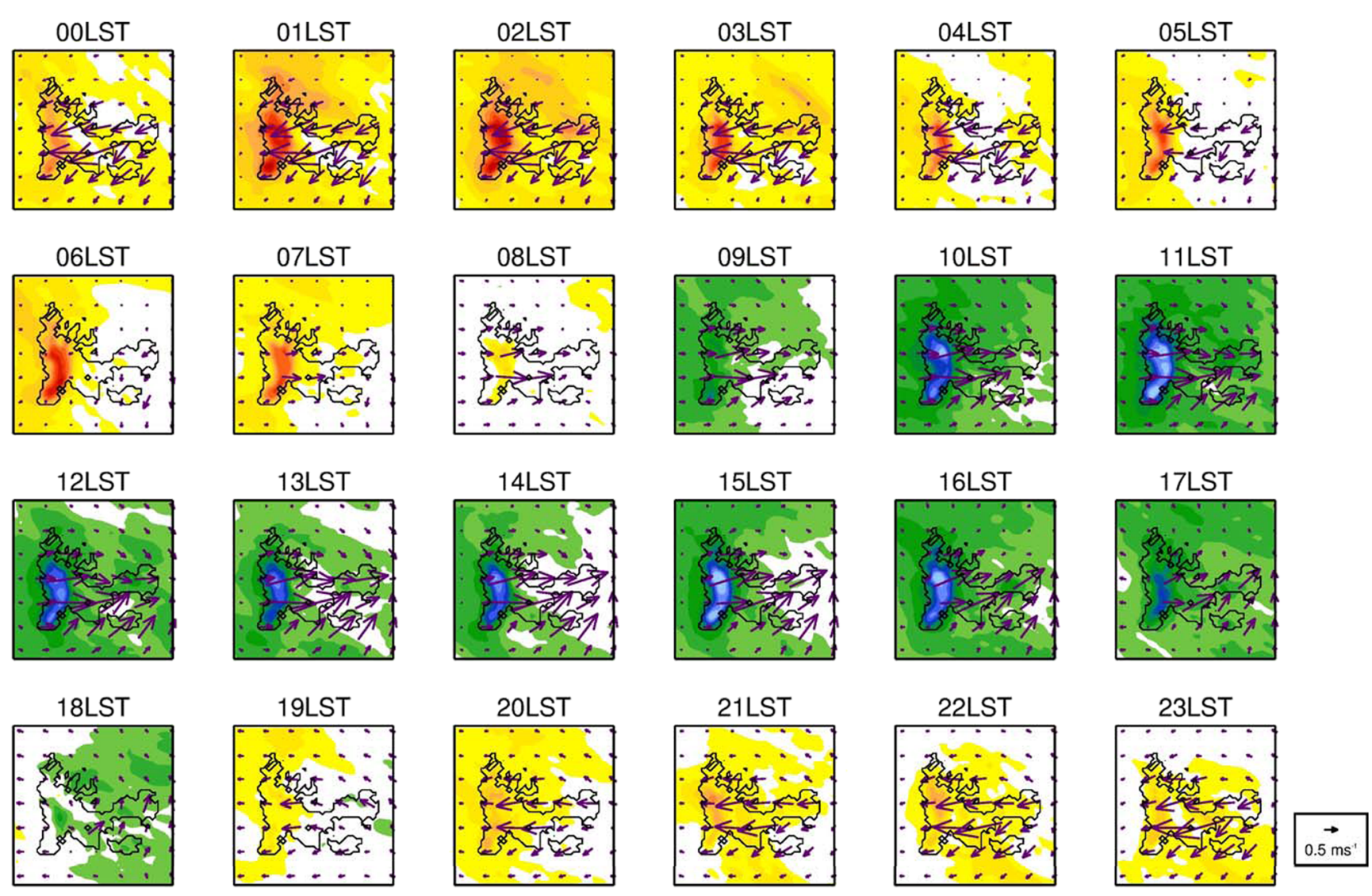

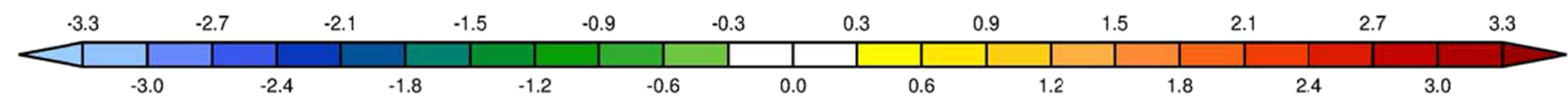

Fig. 10 Regression intercept of the hourly precipitation rate (shading; $\mathrm{mm} \mathrm{day}{ }^{-1}$ ) and $10-\mathrm{m}$ horizontal wind vector (arrows; $\mathrm{m} \mathrm{s}^{-1}$ ) against the conventional ENSO index for the summer season (DJF) in local solar

time (LST). The precipitation and 10-m horizontal wind vector shown are anomalies with respect to the daily mean

ENSO conditions given by the regression intercept resembles the seasonal mean diurnal cycle (not shown). It is important to stress that diurnal cycles are not an exclusive tropical phenomena, in the mid-latitudes topography-driven diurnal cycles have been reported for example on the edges of the Tibetan Plateau (Liu et al. 2009; Guo et al. 2014). Figure 11 shows the regression coefficient. There is a persistent increase in the rainfall more significant during nighttime and morning hours and just to the east of the Cook Ice Cap, in the same region where the statistically significant increment in the seasonal mean precipitation shown in Fig. 9 is observed. The most pronounced increase in precipitation takes place between 1 and 2 LST when the anomalous wind associated with the diurnal cycle is easterly and with the El Niño is westerly, in phase with the background winds, suggesting that the resulting increased horizontal wind convergence may explain the enhanced precipitation. From late morning to late afternoon, Fig. 11 shows anomalous northerly winds in El Niño conditions over the Loranchet and Railler du Baty Peninsulas as well as over parts of Ronarc'h and Jeanne d'Arc Peninsulas with the increase in precipitation gradually shifting eastwards towards the Courbet Peninsula before drier conditions set in from 18 to 22 LST. A comparison of Fig. 11 with Fig. 10 indicates that ENSO affects both the amplitude and phase of the diurnal cycle. It can be concluded that the main mechanism whereby conventional ENSO events act to increase the local precipitation over central parts of the islands, mainly to the east of the Cook Ice Cap, in DJF is through changes in the seasonal mean diurnal cycle.

The interaction with the diurnal cycle reported for conventional ENSO events is not exclusive to this mode of variability and to the summer season even though in the other seasons the amplitude of the precipitation diurnal cycle is smaller (about a third in the shoulder seasons and a sixth in the winter season). 

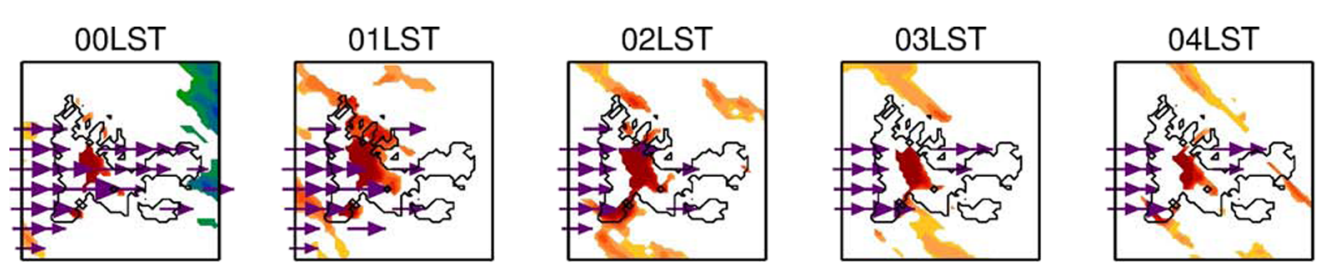

05LST

06LST

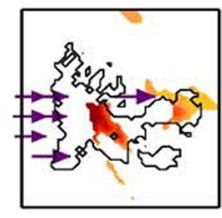

12LST

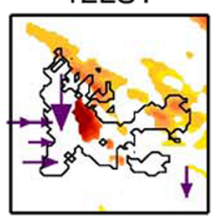

18LST

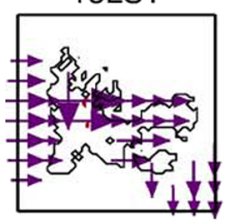

08LST

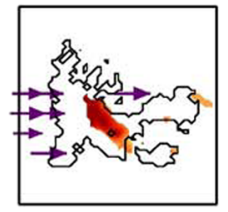

13LST

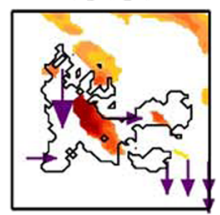

19LST

14LST

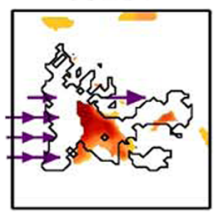

09LST

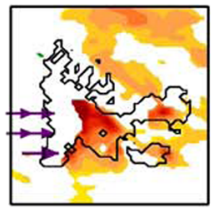

10LST
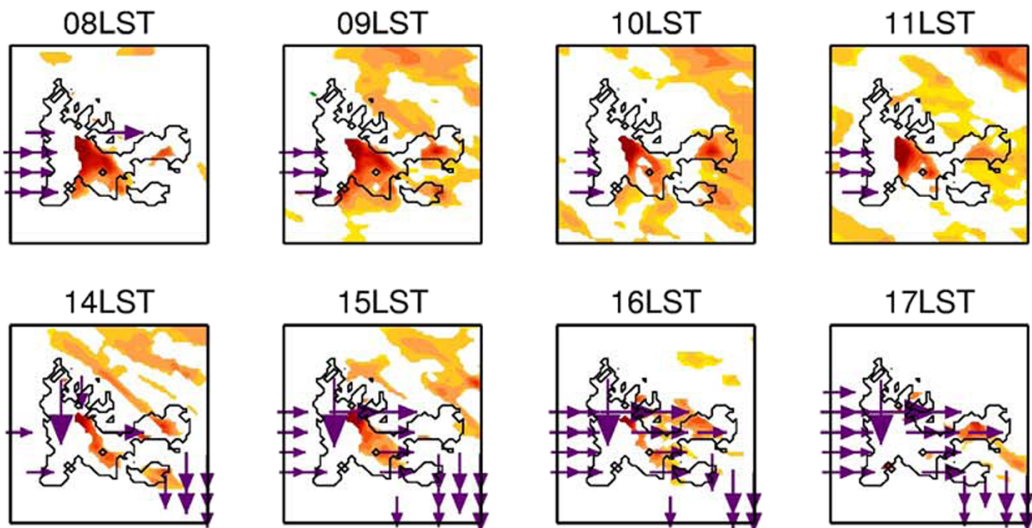

15LST

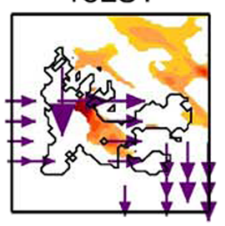

16LST

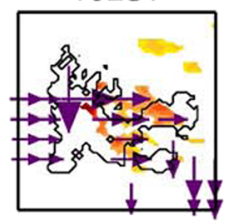

17LST

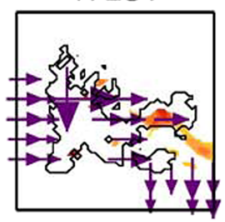

21LST
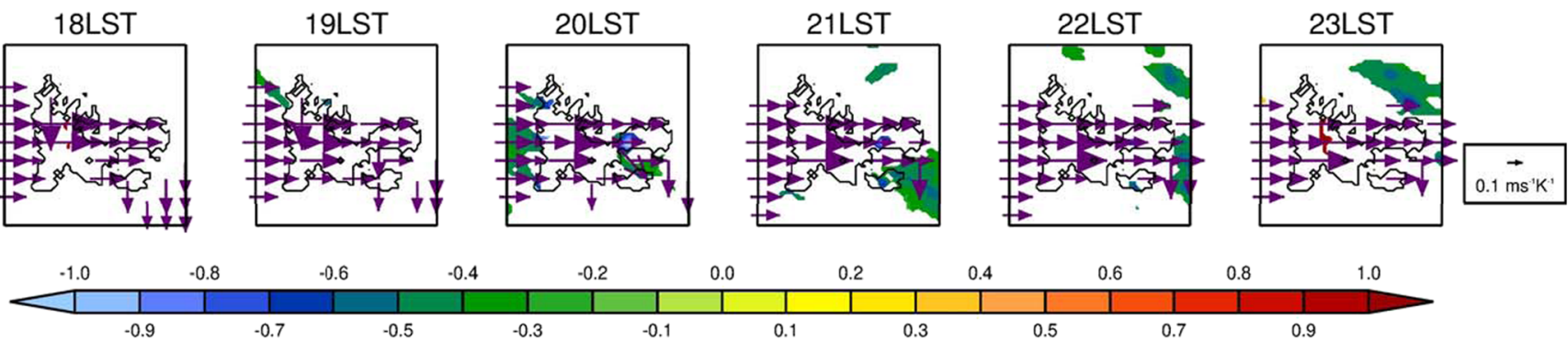

Fig. 11 Regression coefficient of DJF hourly precipitation rate (shading; $\mathrm{mm} \mathrm{day}^{-1} \mathrm{~K}^{-1}$ ) and 10 - $\mathrm{m}$ horizontal wind vector (arrows; $\mathrm{m} \mathrm{s}^{-1} \mathrm{~K}^{-1}$ ) against the conventional ENSO index. The conventions are as in Fig. 9

For the other modes of variability considered, and for brevity purposes, only the regression coefficients against the seasonal mean fields will be shown.

Figure 12 shows the regression coefficient with respect to ENSO Modoki. A comparison with Fig. 9 reveals that overall the impact of ENSO Modoki events on the seasonal mean climate is smaller compared to that of conventional ENSO events. In DJF and in El Niño Modoki events, the increase in precipitation to the east of the Cook Ice Cap and the decrease in south-western parts of the Railler du Baty Peninsula are mainly a result of the interaction with the diurnal cycle. However, and as opposed to conventional El Niño events, this occurs mostly through changes in the amplitude. The other season for which there are statistically significant changes in precipitation is the autumn when heavier rainfall around Whaler's Bay is predicted by the model in El Niño Modoki events. The lower sea surface temperatures cannot account for this increase in rainfall which is also found to result mainly from the interaction with the diurnal cycle.
The next mode of variability considered is the IOD with the regression coefficients shown in Fig. 13. Statistically significant changes in precipitation are observed mainly over the ocean and in the winter and spring seasons. In JJA, the increase in precipitation can be explained by the higher sea surface temperatures, whereas in spring drier atmospheric weather conditions lead not only to an increase in surface evaporation (with strong positive, upward from the surface, latent heat fluxes) but also to a reduction in precipitation.

The regression coefficients for SIOD are given in Fig. 14. The changes in precipitation for the summer season in SIOD+ events resemble those obtained for conventional El Niño events and result from the same mechanism but have the opposite sign. The drier conditions predicted by the model over land are also consistent with the increased surface evaporation. In spring, the higher SSTs around the islands can explain the local increase in precipitation in parts of the Railler du Baty Peninsula in SIOD+ events. In JJA, the interaction with the diurnal cycle mostly accounts for the increase in 

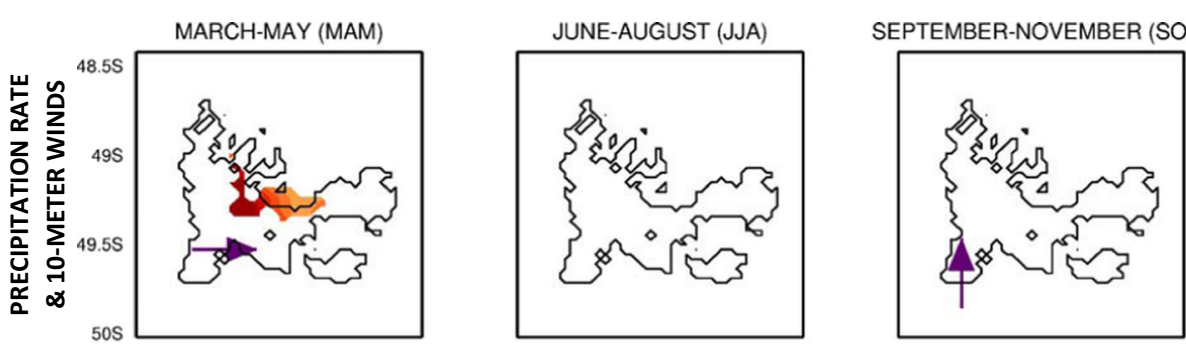

DECEMBER-FEBRUARY (DJF)
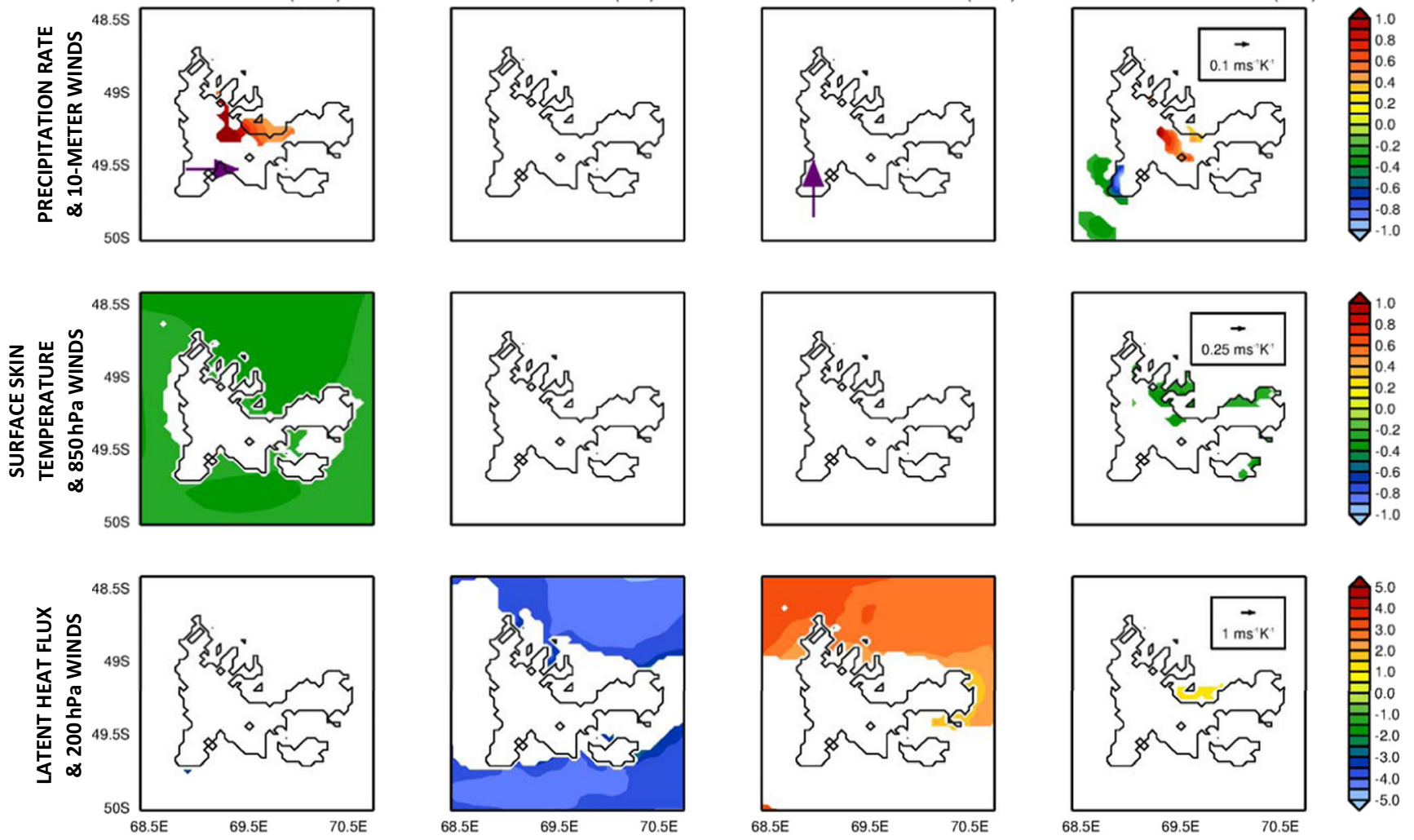

Fig. 12 As Fig. 9 but for a linear regression against the ENSO Modoki index
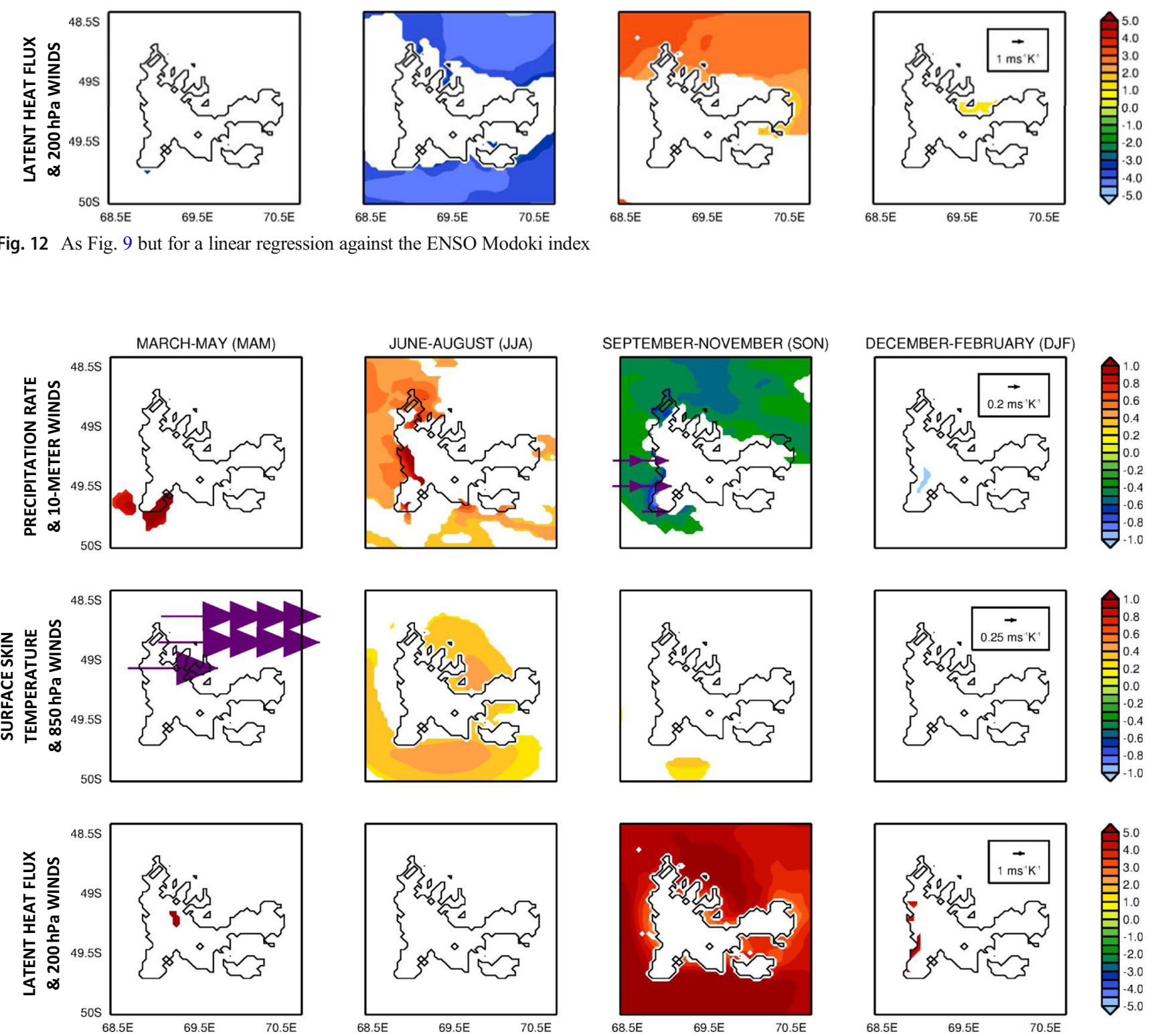

Fig. 13 As Fig. 9 but for a linear regression against the IOD index

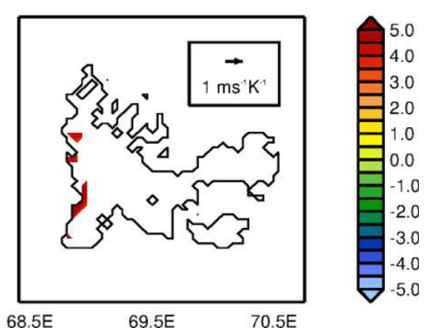



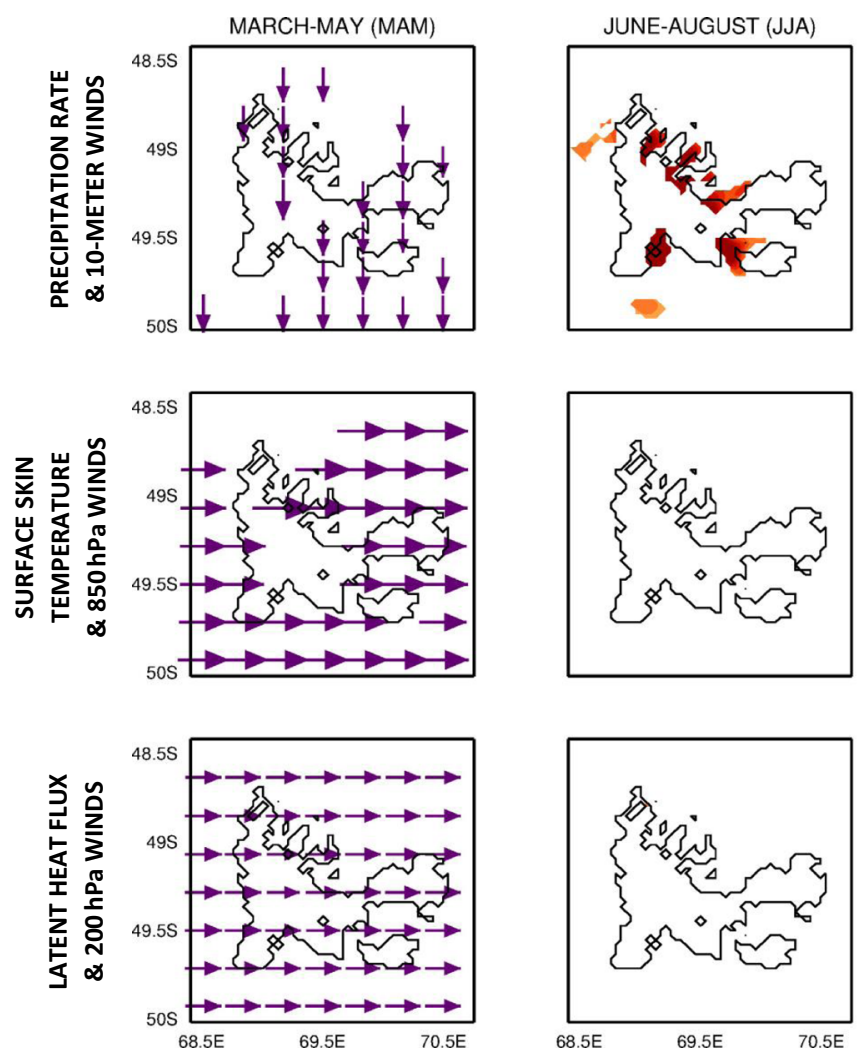

Fig. 14 As Fig. 9 but for a linear regression against the SIOD index
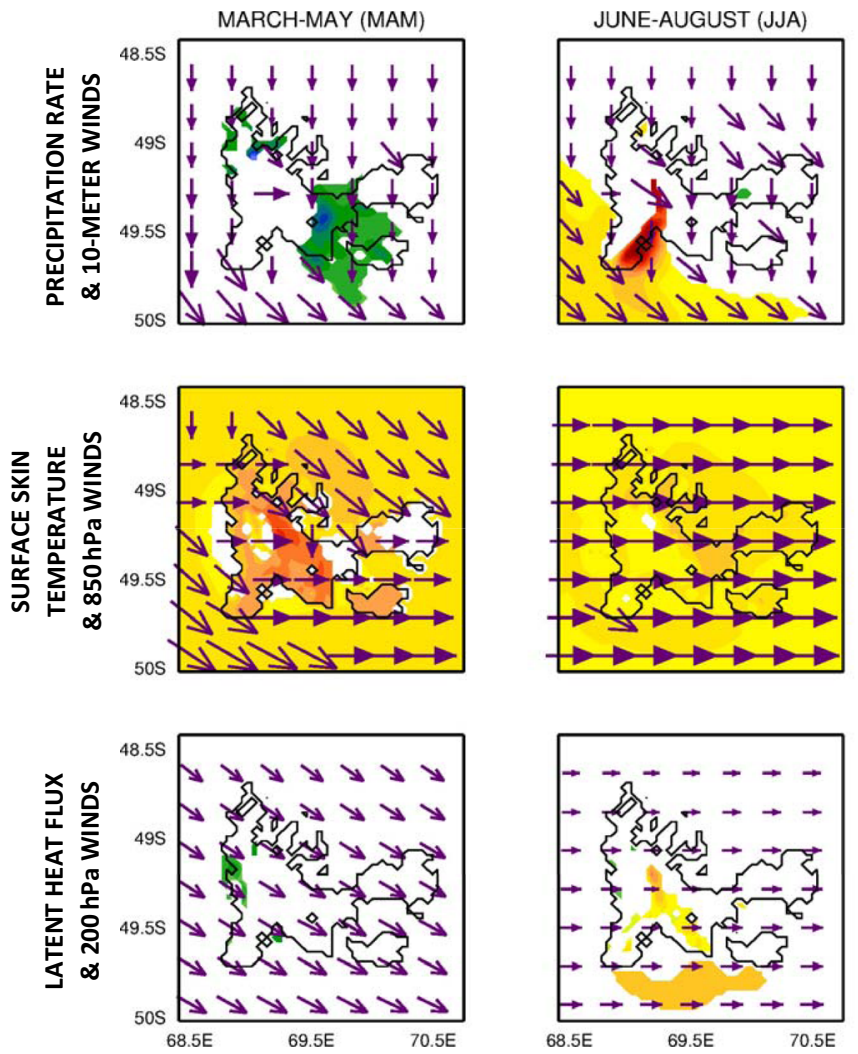

Fig. 15 As Fig. 9 but for a linear regression against the SAM index

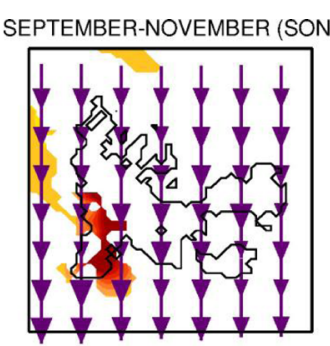

DECEMBER-FEBRUARY (DJF)
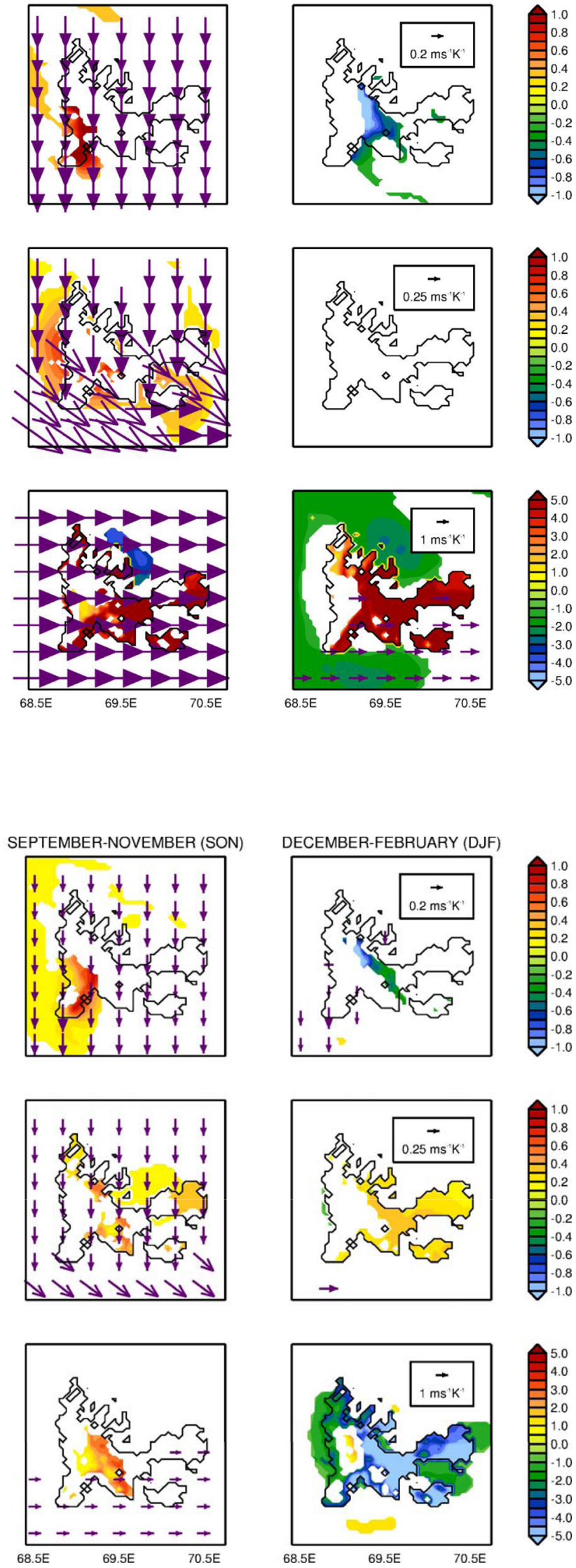

Springer 
precipitation in some coastal regions. As is the case for conventional ENSO events, the interaction of the SIOD with the precipitation diurnal cycle occurs through changes in amplitude and phase.

The final mode of variability considered is SAM with the regression coefficients given in Fig. 15. Unlike the other modes, SAM has a direct effect on the seasonal mean climate of the Kerguelen Islands as it is related to variations in the position and strength of the storm track that impacts the islands. As discussed in Favier et al. (2016), the recent increase in the SAM index and resultant poleward shift of the storm track has led to generally drier conditions in the islands. As seen in Fig. 15, this is the case in spring and summer but in winter and autumn, the model predicts an increase in precipitation mainly off the south-east coast of the Railler du Baty Peninsula and in parts of the Cook Ice Cap. Higher surface temperatures, coupled with the interaction of the anomalous northerly and north-westerly winds associated with SAM+ events with the local topography, background winds and seasonal mean diurnal cycle, explain the predicted precipitation changes. As is the case with conventional ENSO and SIOD, SAM modulates both the amplitude and phase of the precipitation diurnal cycle.

\section{Conclusions}

In this paper, we investigate the climate mean and inter-annual variability of the Kerguelen Islands using the hourly output of a $3 \mathrm{~km}$ horizontal resolution WRF run performed over a 30-year period from April 1986 to March 2016. The model output is first evaluated against station data, as given by the NOAA GSOD dataset, and radiosonde data, given by NOAA IGRA, for the Port-aux-Français station, the only location in the island for which observational data is available. The diagnostic suite proposed by Koh et al. (2012) is employed to assess the model performance. With respect to station data, the main model biases are a lower daily-mean temperature by about 1 to $2 \mathrm{~K}$ (mostly due to lower maximum temperatures suggesting excessive low-level cloud cover in the model), heavier precipitation (in particular in the winter season) and weaker daily-mean wind speeds (larger biases in the summer season with a magnitude of up to $\sim 2 \mathrm{~ms}^{-1}$ ). A comparison with radiosonde data reveals a more moist atmosphere in the model throughout the whole column (1000 to $200 \mathrm{hPa})$. The lower surface temperatures coupled with higher temperatures in the 950-700 hPa layer and lower temperatures above in the $700-550 \mathrm{hPa}$ region are also consistent with increased low-level cloud cover. Despite the referred biases, the WRF performance is found to be rather good for all fields and seasons considered.

Having verified that the model data is generally in good agreement with that observed for the Port-aux-Français station, the seasonal mean climate is then analysed. In line with
Favier et al. (2016), the precipitation is found to increase with height reaching a maximum at the highest elevations of the Cook Ice Cap in the winter season. Eastern and southern portions of the Courbet Peninsula and the low-land areas between the Gallieni and Courbet Peninsulas and of the Jeanne d'Arc and Ronarc'h Peninsulas have the lowest seasonal mean precipitation amounts. These regions also experience the highest seasonal mean surface temperatures that do not exceed $9{ }^{\circ} \mathrm{C}$. Conversely, the $0{ }^{\circ} \mathrm{C}$ isotherm lies close to the top of the Cook Ice Cap in the summer season indicating that any future warming is bound to have a large impact on the existing glaciers. The low-level winds are generally westerly to northwesterly with maximum seasonal mean speeds in excess of $17 \mathrm{~m} \mathrm{~s}^{-1}$ at the highest elevations of the Cook Ice Cap and lower speeds along the west coast and in the low-land regions of the central and eastern parts of the islands where they are typically less than $6 \mathrm{~m} \mathrm{~s}^{-1}$.

The influence of five modes of variability (conventional and Modoki ENSO, IOD, SIOD and SAM) on the seasonal mean climate is then investigated through linear regression. The focus is on the precipitation given its recent decline and major role in the glacier wastage reported at the Cook Ice Cap (Verfaillie et al. 2015; Favier et al. 2016).

For ENSO, the largest impact is for conventional events and in the summer season with higher amounts of rainfall in El Niño events just to the east of the Cook Ice Cap and low elevations between the Gallieni and Courbet Peninsulas. The fact that the largest response occurs in DJF is not surprising as ENSO events typically reach their largest magnitude in this season. A further analysis revealed that the referred increase in precipitation is mainly a result of the interaction between the seasonal mean diurnal cycle and the atmospheric circulation associated with ENSO. The precipitation diurnal cycle at the Kerguelen Islands has a similar phase throughout all seasons but, as expected, a larger amplitude in the summer season (on average, and with respect to the summer season, the amplitude is reduced by a factor of three in autumn and spring and further reduced by a factor of two in winter). During daytime, the higher surface temperatures in the lower elevations of the central and eastern parts of the islands lead to lower pressures compared to those further west. Westerly low-level winds develop that are in phase with the background winds giving generally drier conditions. At night, the pattern reverses with the easterly winds, which arise in response to the lower temperatures and associated higher pressures over the central and eastern portions of the islands, converging with the background westerly winds and leading to wetter conditions. Topography-driven diurnal cycles in mid-latitudes have been reported elsewhere including around the edges of the Tibetan Plateau (Liu et al. 2009; Guo et al. 2014).

The impact of IOD on the seasonal mean climate is largest during winter and spring, when these events normally reach peak intensity, and over the surrounding oceans. Changes in 
the surface skin temperature and atmospheric moisture can account for the predicted increase in precipitation in JJA and decrease in SON. SIOD has the largest impact in the summer season. As is the case for conventional ENSO events, this interaction occurs through changes in the diurnal cycle's phase and amplitude but with the opposite effect of decreased precipitation rates (and subsequent increased surface evaporation) in central and eastern parts of the island. The interaction with the diurnal cycle also seems to at least partly account for the predicted increase in rainfall in some coastal areas in the winter season. An increase in the SAM index leads to a poleward shift of the Southern Hemisphere storm track and consequently drier weather conditions at the Kerguelen Islands. While this seems to be the case mainly in central and eastern portions of the islands in summer and autumn seasons, in winter and spring there is increased rainfall over portions of the Cook Ice Cap and south-western parts of the Railler du Baty Peninsula. Modelling results showed that the higher sea surface temperatures around the island and the interaction of the anomalous winds associated with SAM+ events with the local topography, background winds and diurnal cycle can explain the predicted precipitation increase.

The analysis of the WRF experiment presented in this paper highlights the complex nature of the flow around the Kerguelen Islands. Despite being small in size and located at about $50^{\circ} \mathrm{S}$, between the Roaring Forties and the Furious Fifties, with persistently strong westerly winds and a small annual cycle, the precipitation field shows strong interactions with the different modes of variability considered with changes in the diurnal cycle accounting for a significant fraction of that variability. These results may be applicable to other islands located at similar latitudes in the Southern Hemisphere such as the Heard Island and McDonald Islands, Crozet Islands, Marion Islands, Prince Edward Island, Campbell Island and Auckland Island.

Acknowledgments The simulations presented in this paper were performed on resources provided by the Swedish National Infrastructure for Computing (SNIC) at the High Performance Computing Center North (HPC2N). We would like to thank an anonymous reviewer for his detailed and insightful comments and suggestions that helped to improve the quality of the paper.

\section{Verification diagnostics}

$$
\boldsymbol{D}=\boldsymbol{F}-\boldsymbol{O}
$$

$$
\mathrm{BIAS}=\langle\boldsymbol{D}\rangle=\langle\boldsymbol{F}\rangle-\langle\boldsymbol{O}\rangle
$$

$$
\boldsymbol{\mu}=\frac{\langle\boldsymbol{D}\rangle}{\sigma_{D}}
$$

$$
\begin{aligned}
& \rho=\frac{1}{\sigma_{O} \sigma_{F}}\langle(\boldsymbol{F}-\langle\boldsymbol{F}\rangle) \cdot(\boldsymbol{O}-\langle\boldsymbol{O}\rangle)\rangle, \quad-1 \leq \rho \leq 1 \\
& \eta=\frac{\sigma_{O} \sigma_{F}}{\frac{1}{2}\left(\sigma_{O}^{2}+\sigma_{F}^{2}\right)}, \quad 0 \leq \eta \leq 1 \\
& \alpha=\frac{\sigma_{D}^{2}}{\sigma_{O}^{2}+\sigma_{F}^{2}} \equiv 1-\rho \eta, \quad 0 \leq \alpha \leq 2
\end{aligned}
$$

In the equations above, $\mathbf{D}$ is the discrepancy between the model forecast $\mathbf{F}$ and the observations $\mathbf{O} ; \sigma_{X}$ is the standard deviation of $\mathbf{X} ; \boldsymbol{\mu}$ is the normalised bias; $\rho$ is the correlation; $\eta$ is the variance similarity; $\alpha$ is the normalised error variance. $\mathrm{A}$ random forecast has $\alpha=1$ so that $\alpha<1$ is recommended. More information about these diagnostics can be found in Koh et al. (2012).

Open Access This article is distributed under the terms of the Creative Commons Attribution 4.0 International License (http:// creativecommons.org/licenses/by/4.0/), which permits unrestricted use, distribution, and reproduction in any medium, provided you give appropriate credit to the original author(s) and the source, provide a link to the Creative Commons license, and indicate if changes were made.

\section{References}

Ashok K, Behera SK, Rao SA, Weng H, Yamagata T (2007) El Niño Modoki and its possible teleconnection. J Geophys Res 112: C11007. https://doi.org/10.1029/2006JC003798

Ashok K, Yamagata T (2009) Climate change: the El Niño with a difference. Nature 461:481-484

Behera SK, Yamagata T (2001) Subtropical SST dipole events in the southern Indian Ocean. Geophys Res Lett 28:327-330

Berthier E, Le Bris R, Mabileau L, Testut L, Rémy F (2009) Ice wastage on the Kerguelen Islands $\left(49^{\circ} \mathrm{S}, 69^{\circ} \mathrm{E}\right)$ between 1963 and $2006 \mathrm{~J}$ Geophys Res 114:F03005. https://doi.org/10.1029/2008JF001192

Chen F, Dudhia J (2001) Coupling an advanced land surface-hydrology model with the Penn State-NCAR MM5 modeling system. Part I: model implementation and sensitivity. Mon Wea Rev 129:569-585

Durre I, Vose RS, Wuertz DB (2006) Overview of the integrated global radiosonde archive. J Clim 19:53-68

Durre I, Vose RS, Wuertz DB (2008) Robust automated quality assurance of radiosonde temperatures. J Appl Meteor Climatol 47:2081-2095

Dyunkerke PG (1991) Radiation fog: a comparison of model simulations with detailed observations. Mon Wea Rev 119:324-341

Evans JP, Westra S (2012) Investigating the mechanisms of diurnal rainfall variability using a regional climate model. J Clim 25:7232-7247

Favier V, Verfaillie D, Berthier E, Menegoz M, Jomelli V, Kay JE, Ducret L, Malbéteau Y, Brunstein D, Gallée H, Park Y-H, Rinterknecht V (2016) Atmospheric drying as the main driver of dramatic glacier wastage in the southern Indian Ocean. Sci Rep 6:32396. https://doi. org/10.1038/srep32396

Frenot Y, Gloaguen JC, Massé L, Lebouvier M (2001) Human activities, ecosystem disturbance and plant invasions in subantarctic Crozet, Kerguelen and Amsterdam Islands. Biol Conserv 101:33-50

Guinet C, Chastel O, Koudil M, Durbec JP, Jouventin P (1998) Effects of warm sea-surface temperature anomalies on the blue petrel at the Kerguelen Islands. Proc R Soc Lond B 265:1001-1006 
Guo J, Zhai P, Wu L, Cribb M, Li Z, Ma Z, Wang F, Chu D, Wang P, Zhang J (2014) Diurnal variation and the influential factors of precipitation from surface and satellite measurements in Tibet. Int $\mathrm{J}$ Climatol 34:2940-2956

Hill KA, Lackmann GM (2009) Analysis of idealized tropical cyclone simulations using the weather research and forecasting model: sensitivity to turbulence parameterization and grid spacing. Mon Wea Rev 137:745-765

Hooker JD (1879) Observations on the botany of Kerguelen Islands. Phil Trans R Soc Lond 168:9-16

Iacono MJ, Delamere JS, Mlawer EJ, Shephard MW, Clough SA, Collins WD (2008) Radiative forcing by long-lived greenhouse gases: calculations with the AER radiative transfer models. J Geophys Res 113:D13103. https://doi.org/10.1029/2008JD009944

Janjić ZI (1994) The step-mountain eta coordinate model: further developments of the convection, viscous sublayer and turbulence closure schemes. Mon Wea Rev 122:927-945

Katata G, Nagai H, Wrzesinky T, Klemm O, Eugster W, Burkard R (2008) Development of a land surface model including cloud water deposition on vegetation. J Appl Meteor Climatol 47:2129-2146

Katata G, Kajino M, Hiraki T, Aikawa M, Kobayashi T, Nagai H (2011) A method for simple and accurate estimation of fog deposition in a mountain forest using a meteorological model. J Geophys Res 116: D20102, doi:10.129/2010JD015552

Koh TY, Fonseca RM (2016) Subgrid-scale cloud-radiation feedback for the Betts-Miller-Janjić convection scheme. Quart J R Met Soc 142: 989-1006

Koh TY, Wang S, Bhatt BC (2012) A diagnostic suite to assess NWP performance. J Geophys Res 117:D13109. https://doi.org/10.1029/ 2011JD017103

Lestari RK, Koh T-Y (2016) Statistical evidence for asymmetry in ENSO-IOD interactions. Atmos - Ocean 54:498-504

Liu X, Bai A, Liu C (2009) Diurnal variations of summertime precipitation over the Tibetan plateau in relational to ographically-induced regional circulations. Environ Res Lett 4:045203

Lo JC, Yang Z, Pilke RA (2008) Assessment of three dynamical climate downscaling methods using the weather research and forecasting (WRF) model. J Geophys Res 113:D09112. https://doi.org/10. 1029/2007JD009216

Marshall GJ (2013) Trends in the southern annular mode from observations and renalysis. J Clim 16:4134-4143

Mills CM (2011) On the Weather Research and Forecasting model's treatment of sea ice albedo over the Arctic Ocean. $10^{\text {th }}$ Annual School of Earth, Society, and Environmental Research Review, $25^{\text {th }}$ February 2011, University of Illinois at Urbana-Campaign, IL

Monin AS, Obukhov AM (1954) Basic laws of turbulent mixing in the ground layer of the atmosphere. Trans. Geophys Inst Akad Nauk USSR 151:163-187

Nakanishi M (2000) Large-eddy simulation of radiation fog. BoundLayer Meteor 94:461-493

Nakanishi M, Niino H (2004) An improved Mellor-Yamada level-3 model with condensation physics: its design and verification. BoundLayer Meteor 119:1-31

Nakanishi M, Niino H (2006) An improved Mellor-Yamada level-3 model with condensation physics: its numerical stability and application to a regional prediction of advection fog. Bound-Layer Meteor 119: 397-407

Poggi A (1977) Heat balance in the ablation area of the ampere glacier (Kerguelen Islands). J Appl Meteorol 16:48-55

Saha S, Moorthi S, Pan H-L, Wu X, Wang J, Nadiga S, Tripp P, Kistler R, Woollen J, Behringer D, Liu H, Stokes D, Grumbine R, Gayno G,
Wang J, Hou Y-T, Chuang H-Y, Juang H-MH, Sela J, Iredell M, Treadon R, Kleist D, Van Delst P, Keyser D, Derber J, Ek M, Meng J, Wei H, Yang R, Lord S, Van Den Dool H, Kumar A, Wang W, Long C, Chelliah M, Xue Y, Huang B, Schemm J-K, Ebisuzaki W, Lin R, Xie P, Chen M, Zhou S, Higgins W, Zou C-Z, Liu Q, Chen Y, Han Y, Cucurull L, Reynolds RW, Rutledge G, Goldberg M (2010) The NCEP climate forecast system reanalysis. Bull Amer Meteor Soc 91:1015-1057

Saji NH, Goswami BN, Vinayachandran PN, Yamagata T (1999) A dipole model in the tropical Indian Ocean. Nature 401:360-363

Saji NH, Yamagata T (2003) Possible impacts of Indian Ocean dipole mode events on global climate. Clim Res 25:151-169

Samala BK, Nagaraju, C, Banerjee S, Kaginalkar SA, Dalvi M (2013) Study of the Indian summer monsoon using WRF-ROMS regional coupled model simulations. Atmosph Sci Lett 14:20-27

Skamarock WC, Klemp JB, Dudhia J, Gill DO, Barker DM, Duda MG, Huang X-Y, Wang W, Power JG (2008) A description of the Advanced Research WRF version 3. NCAR tech. Note TN4175_STR, 113pp

Steele CJ, Dorling SR, von Glasow R, Bacon J (2013) Idealized WRF model sensitivity simulations of sea breeze types and their effects on offshore windfields. Atmos Chem Phys 13:443-461. https://doi.org/ 10.5194/acp-13-443-2013

Tao W-K, Simpson J, McCumber M (1989) An ice-water saturation adjustment. Mon Wea Rev 117:231-235

Taylor KE, Stouffer RJ, Meehl GA (2012) An overview of CMIP5 and the experiment design. Bull Am Meteorol Soc 93:485-498

Tegen I, Hollrig P, Chin M, Fung I, Jacob D, Penner J (1997) Contribution of different aerosol species to the global aerosol extinction optical thickness: estimates from model results. J Geophys Res 102:2389523915

Trenberth KE, Shea DJ (2005) Relationships between precipitation and surface temperature. Geophys Res Lett 32:L14703. https://doi.org/ 10.1029/2005GL022760

Vallon M (1987) Glaciologie à Kerguelen, paper presented at Colloque C.N.F.R.A. sur la Recherche Françaises dans les Terres Australes, Strasbourg, France, 11-17 Sept.

Varney BM (1926) Climate and weather at Kerguelen Islands. Mon Wea Rev 54:425-426

Verfaillie D, Favier V, Dumont M, Jomelli V, Gilbert A, Brunstein D, Gallée H, Rinterknecht V, Menegoz M, Frenot Y (2015) Recent glacier decline in the Kerguelen Islands $\left(49^{\circ} \mathrm{S}, 69^{\circ} \mathrm{E}\right)$ derived from modelling, field observations, and satellite data. J Geophys Res Earth Surf 120:637-654

Wallace AR (1889) Darwinism: an exposition of the theory of natural selection with some of its applications. Library of Alexandria, United States of America

Weimerskirch H, Zotier R, Jouventin P (1989) The avifauna of the Kerguelen Islands. Emu 89:15-29

Weng H, Ashok K, Behera SK, Rao SA, Yamagata T (2007) Impacts of recent el Niño Modoki on dry/wet conditions in the Pacific rim during boreal summer. Clim Dyn 29:113-129

Weng H, Behera SK, Yamagata T (2009) Anomalous winter climate conditions in the Pacific rim during recent el Niño Modoki and el Niño events. Clim Dyn 32:663-674

Zambon JB, He R, Warner JC (2014) Investigation of hurricane Ivan using the coupled ocean-atmosphere-wave-sediment transport (COAWST) model. Ocean Dynam 64:1535-1554

Zeng X, Beljaars A (2005) A prognostic scheme of sea surface skin temperature for modeling and data assimilation. Geophys Res Lett 32:L14605. https://doi.org/10.1029/2005GL023030 